University of South Florida

DIGITAL COMMONS

Digital Commons @ University of

@ UNIVERSITY OF SOUTH FLORIDA

South Florida

3-1-2007

\title{
Satellite-Derived Surface Current Divergence in Relation to Tropical Atlantic SST and Wind
}

\author{
Robert W. Helber \\ University of South Florida \\ Robert $\mathrm{H}$. Weisberg \\ University of South Florida, weisberg@marine.usf.edu \\ Fabrice Bonjean \\ Earth and Space Research
}

Eric S. Johnson

Earth and Space Research

Gary S. Lagerloef

Earth and Space Research

Follow this and additional works at: https://digitalcommons.usf.edu/msc_facpub

Part of the Marine Biology Commons

\section{Scholar Commons Citation}

Helber, Robert W.; Weisberg, Robert H.; Bonjean, Fabrice; Johnson, Eric S.; and Lagerloef, Gary S., "Satellite-Derived Surface Current Divergence in Relation to Tropical Atlantic SST and Wind" (2007). Marine Science Faculty Publications. 152.

https://digitalcommons.usf.edu/msc_facpub/152

This Article is brought to you for free and open access by the College of Marine Science at Digital Commons @ University of South Florida. It has been accepted for inclusion in Marine Science Faculty Publications by an authorized administrator of Digital Commons @ University of South Florida. For more information, please contact digitalcommons@usf.edu. 


\title{
Satellite-Derived Surface Current Divergence in Relation to Tropical Atlantic SST and Wind
}

\author{
Robert W. Helber* and Robert H. Weisberg \\ College of Marine Science, University of South Florida, Saint Petersburg, Florida \\ Fabrice Bonjean, Eric S. Johnson, and Gary S. E. Lagerloef \\ Earth and Space Research, Seattle, Washington
}

(Manuscript received 10 August 2005, in final form 11 August 2006)

\begin{abstract}
The relationships between tropical Atlantic Ocean surface currents and horizontal (mass) divergence, sea surface temperature (SST), and winds on monthly-to-annual time scales are described for the time period from 1993 through 2003. Surface horizontal mass divergence (upwelling) is calculated using surface currents estimated from satellite sea surface height, surface vector wind, and SST data with a quasi-linear, steadystate model. Geostrophic and Ekman dynamical contributions are considered. The satellite-derived surface currents match climatological drifter and ship-drift currents well, and divergence patterns are consistent with the annual north-south movement of the intertropical convergence zone (ITCZ) and equatorial cold tongue evolution. While the zonal velocity component is strongest, the meridional velocity component controls divergence along the equator and to the north beneath the ITCZ. Zonal velocity divergence is weaker but nonnegligible. Along the equator, a strong divergence (upwelling) season in the central/eastern equatorial Atlantic peaks in May while equatorial SST is cooling within the cold tongue. In addition, a secondary weaker and shorter equatorial divergence occurs in November also coincident with a slight SST cooling. The vertical transport at 30-m depth, averaged across the equatorial Atlantic Ocean between $2^{\circ} \mathrm{S}$ and $2^{\circ} \mathrm{N}$ for the record length, is $15( \pm 6) \times 10^{6} \mathrm{~m}^{3} \mathrm{~s}^{-1}$. Results are consistent with what is known about equatorial upwelling and cold tongue evolution and establish a new method for observing the tropical upper ocean relative to geostrophic and Ekman dynamics at spatial and temporal coverage characteristic of satellite-based observations.
\end{abstract}

\section{Introduction}

Critical elements of the coupled ocean-atmosphere system are the equatorial Atlantic and Pacific Ocean cold tongues, which set the sea surface temperature (SST) gradients of the Tropics (e.g., Wang et al. 2004). Equatorial cold tongues are globally important since equatorial variability is linked with larger-scale climate variability by tropical ocean-atmosphere feedbacks (e.g., Saravanan and Chang 2004). Tropical Atlantic variability is also linked with longer-time-scale global

\footnotetext{
* Current affiliation: Naval Research Laboratory, Stennis Space Center, Mississippi.

Corresponding author address: Robert W. Helber, Naval Research Laboratory, Stennis Space Center, MS 39529.

E-mail: helber@nrlssc.navy.mil
}

variability through the meridional overturning circulation (MOC). This is because equatorial processes govern the MOC upper-limb northward heat transport through the Tropics (e.g., Philander and Pacanowski 1986; Mayer and Weisberg 1993). Continued analyses of tropical Atlantic Ocean processes are therefore warranted.

In the present paper satellite-derived surface current observations from 1993 to 2003 will be discussed with a focus on near-surface horizontal mass divergence (or upwelling). There are several methods for estimating surface current divergence from observations, each with their own strengths and limitations. For example, equatorial divergence estimates from moored arrays at individual locations (e.g., Weingartner and Weisberg 1991a; Weisberg and Qiao 2000; Helber and Weisberg 2001), divergence estimates from shipboard acoustic Doppler current profiler (ADCP) sections (e.g., Moli-

DOI: $10.1175 / \mathrm{JPO} 3052.1$ 
nari et al. 2003), and divergence estimated from surface wind and hydrography data (e.g., Meinen et al. 2001) have been performed. Surface drifting buoy arrays are also becoming large enough to provide $1^{\circ}$ gridded fields of the surface current annual cycle in the tropical Atlantic, but gridded fields on shorter or longer time scales are not presently possible (R. Lumpkin 2005, personal communication). Space-based observations have the drawback of providing only ocean surface information but with the benefit of nearly global spatial coverage. For the purpose of exploring the large-scale spatial variability of surface current divergence on monthly-to-interannual time scales, satellite observations provide a useful perspective for diagnosing tropical upper-ocean variability.

In this analysis 11 years (1993-2003) of satellitederived surface currents and horizontal divergence are examined relative to tropical Atlantic SST and wind variability. While surface current analyses cannot be used to examine divergence at depth, the satellite spatial coverage can be used to explore the horizontal variability of the near-surface signature of upwelling throughout the tropical oceans. A goal of this analysis is to describe the strengths and limitations of satellitederived surface currents for diagnosing the vertical velocity of the upper ocean. With this established, analyses such as upper-ocean heat transport can be conducted using similar methods.

\section{Background}

Our concern is mainly with the low frequency nearequatorial circulation on time scales of weeks or longer that is characterized by relatively strong zonal flows. The meridional velocity component is weak relative to the zonal component but the meridional divergence is the major contributor to the vertical velocity component found near the equator. An explanation for this three-dimensional circulation is the "visco-inertial" dynamics described by Charney (1960) and expanded upon by Charney and Spiegel (1971). The inertial dynamics stem from the horizontal Coriolis force sign change at the equator. This coupled with strong easterly winds results in near-surface Ekman divergence, while in the subsurface geostrophic convergence occurs within the thermocline associated with an eastward zonal pressure gradient force. Friction becomes important because of the planetary vorticity gradient. As water within the thermocline moves equatorward, planetary vorticity decreases, requiring a gain of relative vorticity that produces the eastward-flowing Equatorial Undercurrent (EUC: e.g., Fofonoff and Montgomery 1955; Cane 1980). Relative vorticity must be dissipated or physically unrealistic velocity structure would occur at the equator (i.e., a cuspate EUC).

Since the flow is divergent near the surface and convergent within the thermocline, strong vertical circulation occurs that is upward above the EUC core and potentially downward below. Relatively vigorous mixing modifies water from the thermocline either upward toward the surface or downward beneath the thermocline. Near the surface the water is warmed and then transported poleward by Ekman divergence. Beneath the equatorial thermocline water that is downwelled mixes in order to maintain the relatively constant density and temperature of the $13^{\circ} \mathrm{C}$ thermostad. Observational support of the visco-inertial dynamics is given by Qiao and Weisberg (1997), and Wang (2005) expands on the related subthermocline circulation cells.

Several studies show additional observational evidence for equatorial vertical velocity profiles that are upward above the EUC and downward below in regions of strong easterly trade winds and eastwarddirected zonal pressure gradient force (e.g., Bryden and Brady 1985; Weingartner and Weisberg 1991a; Weisberg and Qiao 2000; Meinen et al. 2001). In equatorial regions where strong easterlies are absent, the pressure gradient may be reversed and the circulation may be different. For example, in the western equatorial Pacific the thermocline at times slopes up toward the east beneath westerly winds. It was found that under these conditions upwelling still occurs but it is due to geostrophic divergence within the thermocline resulting in relatively deep upwelling (Helber and Weisberg 2001). While satellite-derived surface current divergence estimates cannot detect this type of deep upwelling, they are useful for mapping the near-surface divergence.

The influence of the vertical circulation (upwelling) on SST and the equatorial temperature balance are linked with the seasonal and interannual variability of the tropical ocean-atmosphere system. Weingartner and Weisberg (1991b) found that SST cooling in boreal spring in the central equatorial Atlantic is due to strong vertical advection. More recently, Foltz et al. (2003) demonstrated that on the equator at $10^{\circ} \mathrm{W}, 23^{\circ} \mathrm{W}$, and $35^{\circ} \mathrm{W}$ horizontal temperature advection and entrainment have substantial influence on the temperature budget. Without vertical circulation and entrainment the seasonal development of the cold tongue along the equator in the central and eastern Atlantic (and Pacific) would not exist. Along with an annual cooling of SST in boreal spring/summer, a secondary cooling occurs in November, also as a consequence of easterly winds along the equator. The November cooling may provide an important ocean-atmosphere feedback that could lead to interannual variability in the Atlantic (Oku- 
mura and Xie 2006). Variations in the north-south SST gradient across the equator in the Atlantic are also important since sea surface temperature gradient anomalies are strengthened by positive evaporative feedbacks through the trade winds (Carton et al. 1996; Chang et al. 1997; Xie 1999).

The influence of the three-dimensional equatorial circulation on SST can be seen by comparing the surface current divergence to SST variability. For example, strong divergence (upwelling) increases the entrainment rate of cool water from the upper thermocline by mixing it across isotherms and decreasing SST in the central equatorial Atlantic Ocean (as suggested in Fig. 1). Spatial variability in equatorial Atlantic divergence is characterized by weaker divergence in the west and convergence just north of the equator. Warmer SST tends to coincide with convergence. Away from the equator, geostrophic divergence is substantially weaker where the horizontal Coriolis force varies more slowly with latitude. While tropical divergence appears to have a large influence on SST, surface fluxes and subsurface temperature have substantial influence, particularly poleward of $5^{\circ} \mathrm{S}$ and $10^{\circ} \mathrm{N}$ (Yu et al. 2006).

\section{Near-surface observations and methodology}

The surface current methodology used in this study originated with an analysis of the tropical Pacific Ocean surface velocity by Lagerloef et al. (1999). This original approach used a steady-state model to construct the surface layer currents based on geostrophic and Ekman dynamics derived from observed sea surface height (SSH) and surface vector wind fields. Observations were obtained from satellite platforms, and the mean sea surface height was obtained from an ocean field climatology. The diagnostic model produced geostrophic and Ekman velocity constituents that were analyzed separately.

Shortcomings of the Lagerloef et al. (1999) analysis were a large westward bias in the Pacific cold tongue, lower correlations with Tropical Atmosphere-Ocean (TAO) measurements at the eastern locations, and a failure to resolve the meridional structure of the SEC well enough to discern the two branches. Bonjean and Lagerloef (2002, hereinafter BL02) revised the formulation first by introducing higher-order vertical shear dynamics driven by surface wind consistent with Stommel (1960) and Santiago-Mandujano and Firing (1990). A wind-dependent momentum vertical diffusion coefficient (eddy viscosity A) and the contribution of the SST horizontal gradient to the vertical shear (thermal wind dynamics accounting for buoyancy gradient im-

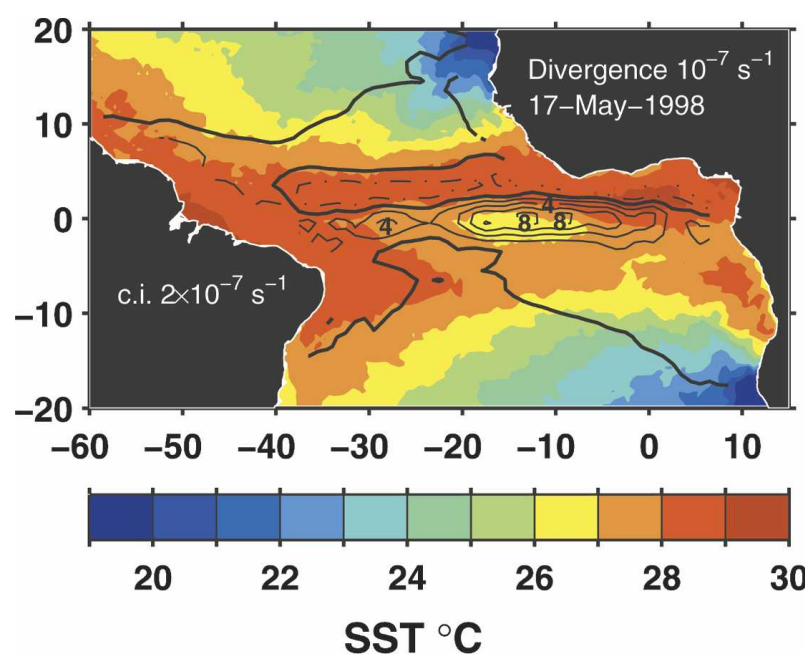

FIG. 1. Pathfinder SST $\left({ }^{\circ} \mathrm{C}\right)$ and $0-30-\mathrm{m}$ depth averaged surface current divergence, both representing an approximate 20-day average centered on 17 May 1998. The contour interval for divergence is $2 \times 10^{-7} \mathrm{~s}^{-1}$. The dash-dot lines are negative, and the zero line is thick.

pact) are also included. The analytical formulations of the vertical shear and surface velocity are derived as a function of sea surface height, surface wind (and stress), and SST gradient, which are all variables from satellite data. The formulations also depend on a depth scale $H$ that is a free parameter of the diagnostic model and subsequently adjusted. Greater skill in the Tropics was achieved and this revised formulation is used in the present analysis. This is also the backbone methodology of the National Oceanic and Atmospheric Administration's (NOAA) Ocean Surface Current Analysis-Real Time (OSCAR). Hereinafter, the BL02 surface currents will be referred to as the OSCAR currents.

An important feature of the BL02 surface current methodology that is exploited in the present analysis is the ability to separate the currents into dynamical constituents of Ekman, geostrophic, and buoyancy gradient forcing. Complications arise within about $2^{\circ}$ or $2.5^{\circ}$ from the equator where the three dynamical constituents individually break down, requiring an alteration to the formulation. A complete discussion of the methods can be found in BL02 but a brief discussion regarding the equatorial solution follows.

The average current over the upper $30 \mathrm{~m}$ is given by

$$
\overline{\mathbf{U}}=\mathbf{U}_{0}+\frac{1}{h} \int_{-h}^{0} \int_{0}^{z} \mathbf{U}^{\prime}(Z) d Z d z,
$$

where $h$ is $30 \mathrm{~m}$ and $\mathbf{U}^{\prime}$ is vertical shear $\left(\mathbf{U}^{\prime}=\partial \mathbf{U} / \partial z\right)$, is analytically known [see BL02, their (6)], and is 
regular everywhere, including on the equator ( $y$ and $f=$ $0)$. Here we are concerned with the surface currents $\mathbf{U}_{0}$ (at $z=0$ ) because this is where the equatorial singularity occurs. Except near the equator, surface horizontal velocity in complex notation $\left(\mathbf{U}_{0}=u_{0}+i v_{0}\right)$ is given by

$$
\text { if } \mathbf{U}_{0}=-g \boldsymbol{\nabla} \zeta+\frac{1}{H} \mathbf{q}\left(\frac{H}{\hbar_{e}}\right) \boldsymbol{\tau}+\frac{H / 2}{\mathbf{q}\left(H / 2 \hbar_{e}\right)} \boldsymbol{\nabla} \theta,
$$

where $f$ is the Coriolis parameter, $g$ is gravity, $\zeta$ is sea surface height, $H$ is the scaling depth, $\hbar_{e}=\sqrt{A / i f}$ is a complex form of the Ekman depth, $\tau=\tau^{x}+i \tau^{y}$ is the vector wind stress, $\theta$ is the simplified buoyancy force, and $\mathbf{q}(\xi) \equiv \xi / \tanh (\xi)$. This formulation is approximately valid as close as $2.5^{\circ}$ from the equator.

At the equator the geostrophic velocity can be related to the second derivative of the surface height field and the wind-driven flow can be expressed in terms of a body force acting in the direction of the surface wind stress. Similar equatorial formulations are found for the buoyancy-gradient term. This is approximated by

$$
\left(\mathbf{U}_{0}\right)_{E}=\frac{i g\left[(\boldsymbol{\nabla} \zeta)_{y}\right]_{E}}{\beta}+\frac{H \boldsymbol{\tau}_{E}}{3 A_{E}}-\frac{i H\left[(\boldsymbol{\nabla} \theta)_{y}\right]_{E}}{2 \beta}-\frac{H^{3}(\boldsymbol{\nabla} \theta)_{E}}{24 A_{E}},
$$

where $E$ represents the equatorial value, $\beta$ is the gradient of the Coriolis parameter with latitude such that $f=\beta y$, and $(\cdots)_{y}$ represents the partial derivative with respect to $y$. A necessary condition for (1) to make a continuous transition to (2) (no singularity) is that the right-hand-side of (1) is zero when $y=0$. The equation that derives from this condition is a simplified equatorial momentum balance also investigated in BL02. It depends on the depth scale $H$, which is adjusted so that departure from this equilibrium in zonal and meridional directions is minimal. From this, $H$ was found equal to about $70 \mathrm{~m}$, which is also the value that implies minimum discrepancy between the calculated velocity and a mean drifter data field extended to the entire basin. Although this adjustment minimizes the impact of the equatorial singularity in the formulation (1), departure from equatorial momentum balance can still be large due to the fact that momentum terms such as local acceleration and momentum advection are neglected. Following this permanent adjustment, the transition from the midlatitude formulation (1) to the approximations on the equator (2) is finally achieved by solving an integral formulation of (1) between a north and a south latitude far enough from the equator $\left(8^{\circ} \mathrm{N}\right.$ and $8^{\circ} \mathrm{S}$ in general). The final solution is expressed as a truncated sum of orthogonal polynomials that come from the integral equation discretization (see BL02 and their ap- pendix A in particular). The result is that (1) and (2) are fitted to these polynomials. Since the equatorial balance adjustment described earlier involves the sum of the three momentum terms representing geostrophic, Ekman, and buoyancy-gradient forcing, they cannot be separated near the equator (the terms are not fit individually). This is only a problem at grid points within $2.5^{\circ}$ from the equator. For this reason, in section 5 , we use the nonfunctionally fitted currents to calculate divergence of the Ekman and geostrophic constituents. The characteristics of equatorial divergence from (1) are discussed in appendix $\mathrm{C}$.

The BL02 formulation provides depth-averaged ( 0 $30 \mathrm{~m}$ ) surface currents estimated from fields of $\mathrm{SSH}$, surface vector winds, and SST on a $1^{\circ}$ grid with the analysis points centered on the half degree. The SSH field is from a gridded product (G. Mitchum 2005, personal communication) constructed using Ocean Topography Experiment (TOPEX)/Poseidon (from October 1992 through June 2002) and Jason-1 (from July 2002 to present) satellite-derived sea surface height (Lagerloef et al. 1999). Surface vector wind is from the Special Sensor Microwave Imager (SSM/I) (Atlas et al. 1996; October 1991 to September 2001) and the Quick Scatterometer (QuikSCAT) gridded winds from the Center for Ocean-Atmosphere Prediction Studies (COAPS; August 2001 to present). For SST we use NOAA Optimum Interpolation (OI) SST V2 data provided by the NOAA-Cooperative Institute for Research in Environmental Sciences (CIRES) Climate Diagnostics Center, Boulder, Colorado. Current estimates are made 36 times per year (every 10 or 11 days) on a $1^{\circ}$ grid. For this analysis the Atlantic OSCAR data were smoothed using optimum interpolation with a two-dimensional exponential decay function with $10^{\circ}$ longitude and $2^{\circ}$ latitude scales and a 40-day low-pass filter. The time period analyzed for this study is from 6 January 1993 until 26 December 2003.

Validation studies and error analyses for the OSCAR currents are given in Johnson et al. (2007). For example, the mean offsets (bias), root-mean-square (rms) differences, correlation, and skill $\langle$ defined as skill = $\{1-[\mathrm{rms}($ difference $)]\} / \mathrm{rms}$ (drifter velocity) $\rangle$ estimated between OSCAR currents and surface drifter fields averaged from $10^{\circ} \mathrm{S}$ to $10^{\circ} \mathrm{N}$ and zonally across the entire tropical Atlantic basin are $0.003 \mathrm{~m} \mathrm{~s}^{-1}, 0.17 \mathrm{~m} \mathrm{~s}^{-1}, 0.78$ and 0.36 for the zonal component and $0.016 \mathrm{~m} \mathrm{~s}^{-1}, 0.12$ $\mathrm{m} \mathrm{s}^{-1}, 0.54$, and 0.02 for the meridional component, respectively.

Further comparisons with data are presented in the sections 4 and 5, where climatologies from surface drifters and ship-drift data are compared with OSCAR currents and divergence. The drifter data, which recently 
reached an array size of greater than 1200 drifters, was acquired from the NOAA/Atlantic Oceanographic and Meteorological Laboratory (Lumpkin and Garraffo 2005; http://www.aoml.noaa.gov/phod/dac/drifter climatology.html). Ship-drift data, which are estimated using the difference between a ship's dead-reckoned position and the navigationally determined position, were acquired from the National Oceanographic Data Center (NODC). In addition, appendix B contains an analysis that relates subsurface temperature data from the Pilot Research Moored Array in the Tropical Atlantic (PIRATA) with equatorial divergence from the OSCAR current estimates.

To explore the relationships of the surface currents and their divergence with other tropical Atlantic Ocean variability, SST and surface zonal wind data are also analyzed. The SST data used for comparisons with divergence in Figs. 1 and 8 are the Advanced Very High Resolution Radiometer (AVHRR) Oceans Pathfinder SST data obtained from the Physical Oceanography Distributed Active Archive Center (PO.DAAC) at the NASA Jet Propulsion Laboratory, Pasadena, California (http://podaac.jpl.nasa.gov). [For additional comparisons in Fig. 12 we use NOAA OI SST V2 and National Centers for Environmental Prediction (NCEP) real-time marine surface zonal wind data provided by the NOAA-CIRES Climate Diagnostics Center from their Web site http://www.cdc.noaa.gov.]

\section{Surface current annual cycle}

The near-surface currents of the tropical Atlantic Ocean are characterized by strong, seasonally modulated zonal components. This can be seen in Fig. 2, where the zonal surface currents at three longitudes are shown from three independent observational sources averaged for each month in climatological fashion. Similar meridional sections were analyzed using shipdrift data by Richardson and McKee (1984). Using essentially the same ship-drift data, in addition to surface drifter data and OSCAR currents, a qualitatively consistent comparison is achieved. The comparison is qualitative since the time frame of each dataset is substantially different and natural variability may account for much of the differences between platforms. For discussion of the variance obtained in the ship-drift data see appendix A.

A prominent feature in these figures is the North Equatorial Countercurrent (NECC) that develops in June/July and last through December (Figs. 2a and 2b) and is a persistent feature of the tropical Atlantic annual cycle. These zonal flow characteristics are also consistent with more recent analyses (Fonseca et al.
2004; Lumpkin and Garzoli 2005). In the eastern portion of the tropical Atlantic eastward flow north of approximately $4^{\circ} \mathrm{N}$ occurs throughout the year (Fig. 2c). The South Equatorial Current (SEC) that appears strongest prior to the onset of the NECC is also evident in the figures. Mostly the three data sources qualitatively agree but in January, February, March, and April near the equator at $15^{\circ} \mathrm{W}$ the OSCAR currents do not capture the strength of the SEC and at some latitudes are going in the opposite direction to the ship-drift and drifter data.

The agreement is remarkably good considering that the averaging period for the OSCAR surface currents is from 1993 to 2002 while that for the ship-drift analysis is for observations made primarily from 1920 to 1940. The ship-drift velocities represent surface currents averaged over the depth of the ship's hull while the OSCAR currents represent a depth average over the upper $30 \mathrm{~m}$. Spatial sampling for the ship-drift velocities represents an average between waypoints usually hundreds of kilometers apart. For the OSCAR currents the filtered estimates represent spatial scales of $2^{\circ}$ latitude and $10^{\circ}$ longitude. The drifter sampling in the Atlantic has seen a recent increase reaching an array size greater than 1250 in 2005. The accuracy of the drifters is potentially superior to that of the ship-drift data since leeway error due to wind effects (Richardson 1997) does not exist with surface drifters affixed with the holey sock drogue (Pazan and Niiler 2001). Due in part the equatorial divergence, however, drifter sampling near the equator is relatively sparse.

To provide a qualitative view of equatorial divergence and to check the consistency of the meridional OSCAR currents, Fig. 3 shows zonal sections at $3^{\circ} \mathrm{N}$ and $3^{\circ} \mathrm{S}$ across the Atlantic Ocean (see appendix B for additional validation of equatorial divergence in OSCAR currents). Note that meridional currents tend to flow northward north of the equator and southward south of the equator, suggesting divergence at the equator. Primarily in the record at $3^{\circ} \mathrm{N}$ we can see stronger northward flow in May, June, and July for longitudes west of $5^{\circ} \mathrm{W}$ and east of $40^{\circ} \mathrm{W}$. East of $5^{\circ} \mathrm{W}$ ship-drift sampling is very low. In this same latitude band stronger northward flow occurs at $3^{\circ} \mathrm{N}$ in November and December. In November this strong northward flow is centered near $20^{\circ} \mathrm{W}$. This suggests a secondary divergence season, which will be discussed later. Similar but weaker and opposite merdional flow tendencies occur at the $3^{\circ} \mathrm{S}$ section. The large northward values to the west at $3^{\circ} \mathrm{S}$ and $3^{\circ} \mathrm{N}$ are associated with the North Brazil Current, which flows northward along the South American coast crossing the equator.

The spatial patterns of the surface currents are de- 


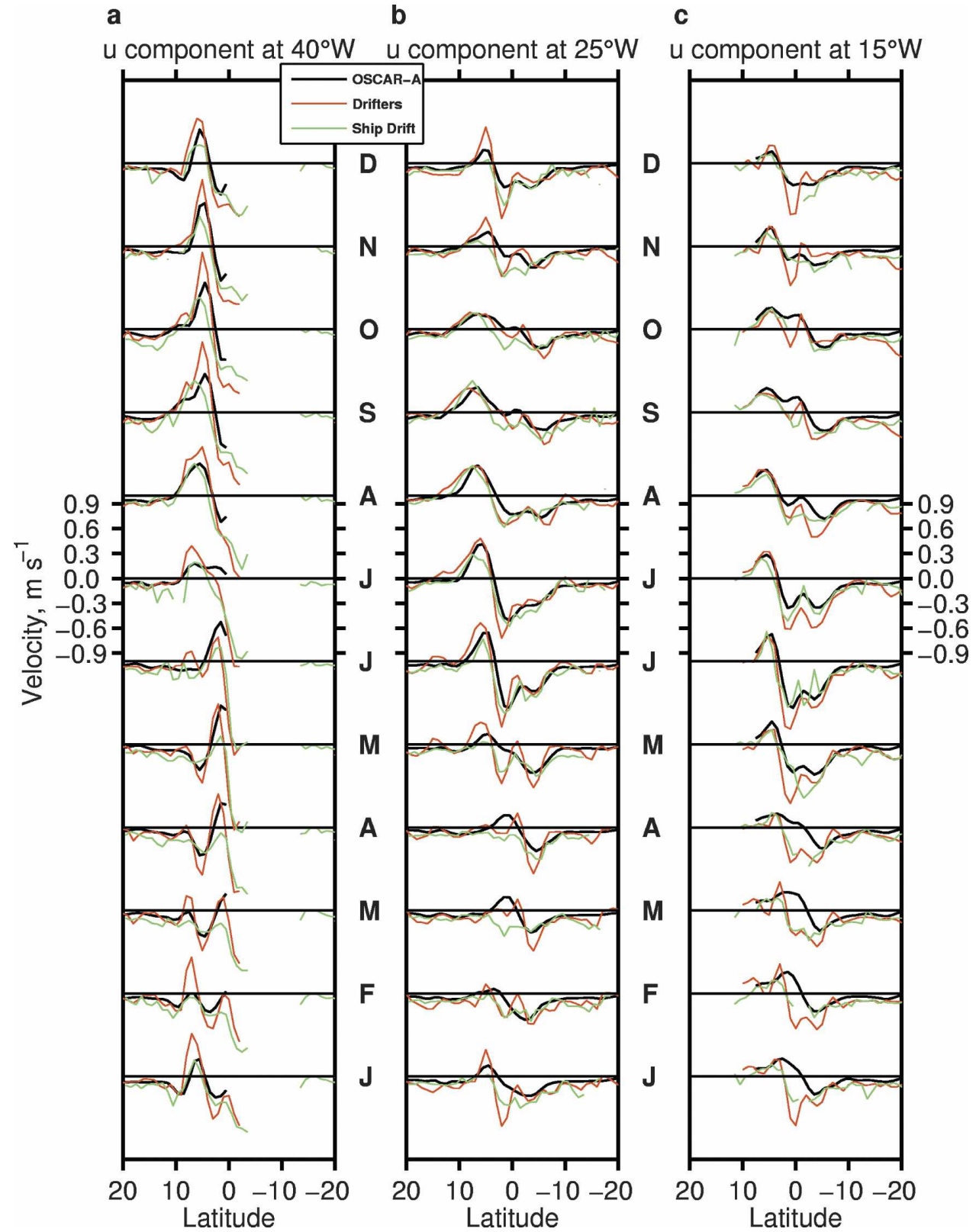

FIG. 2. Meridional sections from $20^{\circ} \mathrm{S}$ to $20^{\circ} \mathrm{N}$ of surface current observations centered at (a) $40^{\circ}$, (b) $25^{\circ}$, and (c) $15^{\circ} \mathrm{W}$ from OSCAR (black), surface drifters (red), and ship-drift (green) data. Positive is eastward flow $\left(\mathrm{m} \mathrm{s}^{-1}\right)$.

scribed using an empirical orthogonal function (EOF) analysis performed separately on east $(u)$ and north $(v)$ climatologically averaged OSCAR velocity components. The latitudinal range is confined within $10^{\circ}$ of the equator because we are focusing on equatorial processes relevant to the cold tongue. The velocity components were analyzed separately since zonal velocities dominate in the tropical oceans. Since the meridional component is responsible for large divergence along the equator, an analysis of just the $v$ component highlights equatorial divergence variability.

Figures $4 \mathrm{a}$ and $4 \mathrm{~b}$ show the time evolution functions and the spatial eigenfunctions of the first two analysis modes. The first mode of the $u$ component $(45 \%$ of total variance) captures the semiannual variability of the NECC and the SEC. Beginning in May the onset of the NECC from approximately $35^{\circ}$ to $15^{\circ} \mathrm{W}$ coincides with a strong SEC. Along the equator the SEC is rep- 


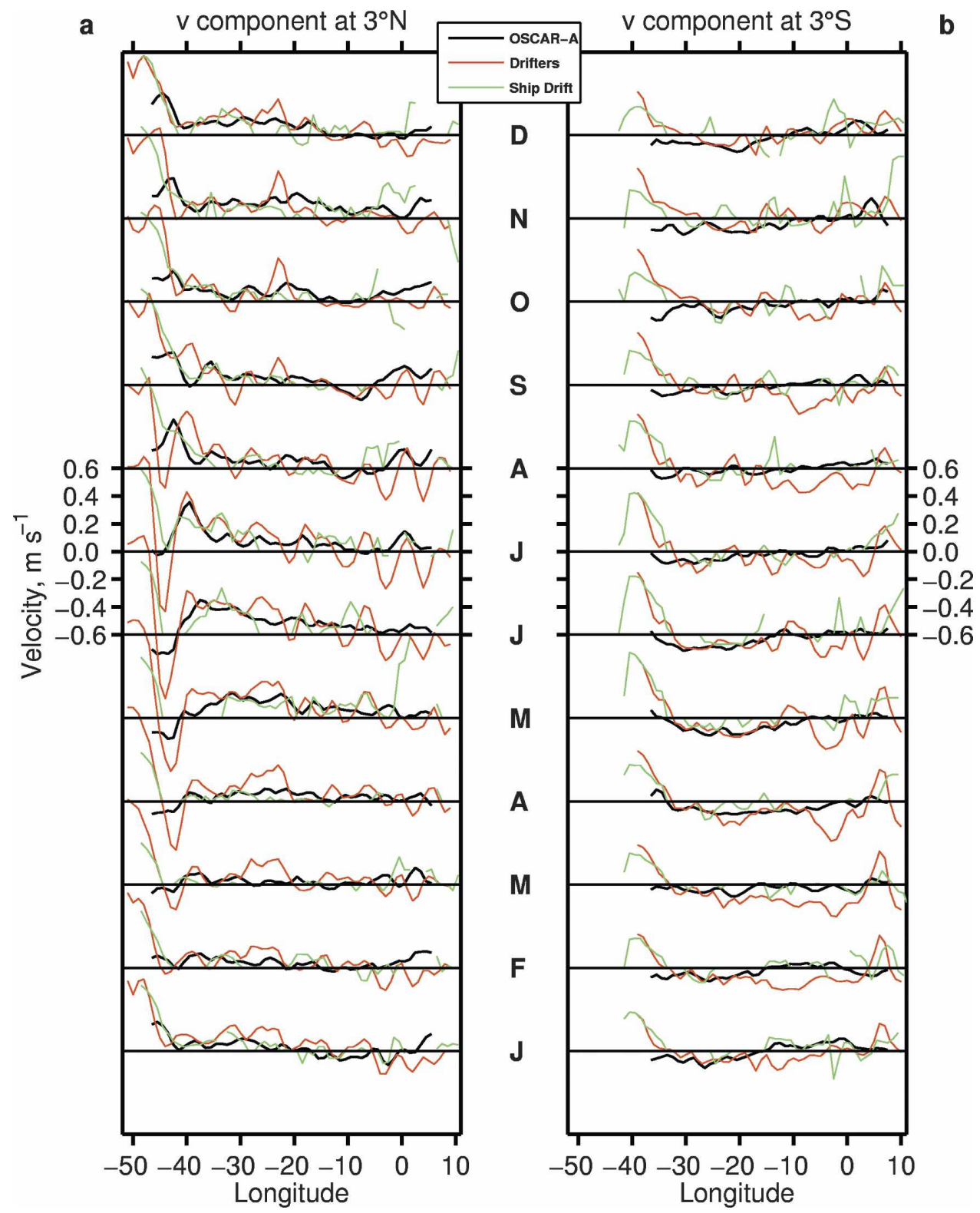

FIG. 3. Zonal sections from $50^{\circ} \mathrm{W}$ to $10^{\circ} \mathrm{E}$ of surface current observations centered at (a) $3^{\circ} \mathrm{N}$ and (b) $3^{\circ} \mathrm{S}$ from OSCAR (black), surface drifters (red), and ship-drift (green) data. Positive is northward flow in units of $\mathrm{m} \mathrm{s}^{-1}$.

resented by the negative contour values and corresponds with the region where surface wind forcing is a dominant factor in SST variability (Carton and Zhou 1997). The second-mode $u$ component (34\% of total variance) captures the annual variability associated with the North Brazil Current eddy shedding and retroflection. Several modes are required to describe this region because variability is space and time dependent.

The modal structure of the $v$ component is reversed with the semiannual variability in the second mode (18\% of total variance; Fig. 5). The bulk of the $v$ com- ponent variability (mode $1 ; 54 \%$ of total variance) is in the west and is associated with the North Brazil Current eddy shedding and retroflection. It is also consistent with the movement of the intertropical convergence zone (ITCZ). This can be seen in the meridional divergence pattern to the west of $40^{\circ} \mathrm{W}$ at $\sim 5^{\circ} \mathrm{N}$. The contour lines that appear nearly horizontal and close together represent strong meridional gradients and divergence. When the time function is positive, this region is divergent in the meridional direction, suggesting cooling in the spring when the ITCZ is farther south. An- 

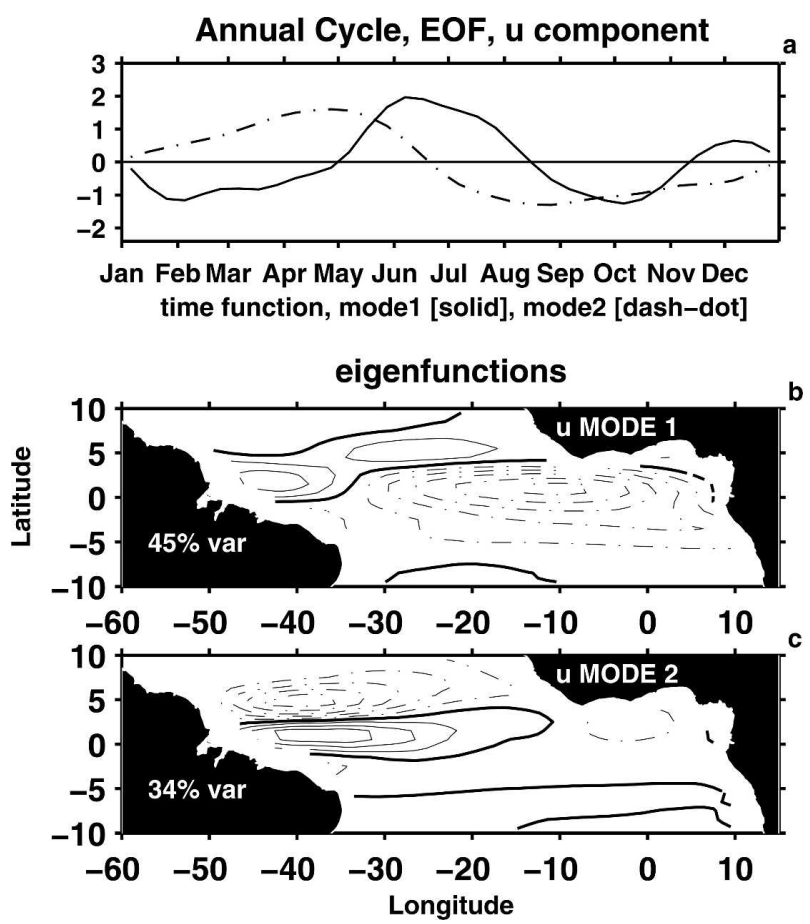

FIG. 4.The first-mode (a) time evolution functions for mode 1 and 2 and the spatial eigenfunctions for (b) mode 1 and (c) mode 2 from two time-domain EOF analyses performed on the climatologically averaged (1993-2003) $u$-component surface currents. In (a), the solid line is for mode 1 and the dash-dot line is for mode 2 . The contour interval is $5 \times 10^{-2} \mathrm{~m} \mathrm{~s}^{-1}$ with negative contours in dash-dot lines, and percent of total variance captured for the first two modes is $45 \%$ and $34 \%$, respectively.

other divergence patterns occurs near the equator just east of $40^{\circ} \mathrm{W}$ but of opposite sign, suggesting convergence (warming) near the equator during the spring when the ITCZ is also near the equator. This divergence pattern is reversed in the autumn when the ITCZ is farther north.

The second-mode $v$ component exhibits a divergence pattern along the equator that peaks in May/June and again in November (Figs. $5 \mathrm{a}$ and $5 \mathrm{c}$ ). From $0^{\circ}$ to $35^{\circ} \mathrm{W}$, along the equator, mode- $2 v$ spatial eigenfunction is positive north of the equator and negative south of the equator, suggesting divergence along the equator when the time evolution function is positive. This will be discussed further in the next section. The third mode (not shown) captures $11 \%$ and $15 \%$ of the total variance for $u$ and $v$, but has variance near the NBC retroflection region where the space and time variances of the surface currents are large.

\section{Horizontal surface current divergence}

To establish the connection between horizontal surface current divergence and upwelling, consider cur-
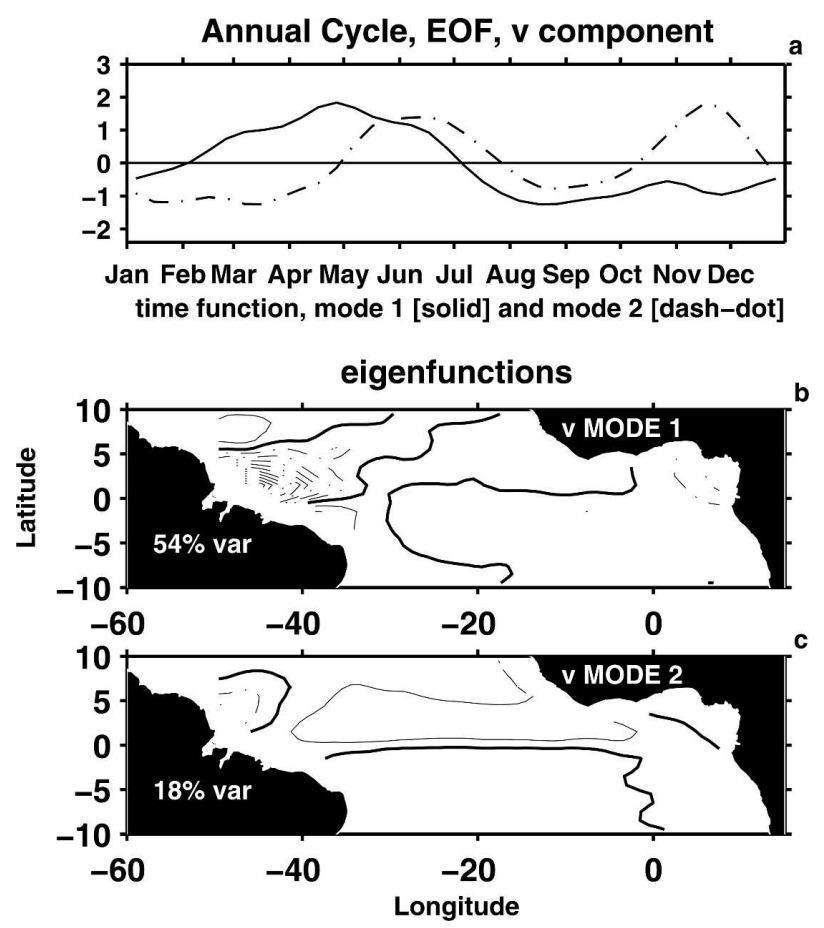

FIG. 5. As in Fig. 4 but for the $v$-component surface currents. Contour interval is $2 \times 10^{-2} \mathrm{~m} \mathrm{~s}^{-1}$ with negative contours in dash-dot lines, and percent of total variance captured for the first two modes is $54 \%$ and $18 \%$.

rents averaged over the upper $30 \mathrm{~m}$ (as with the OSCAR currents) and the continuity equation

$$
\frac{\partial u}{\partial x}+\frac{\partial v}{\partial y}+\frac{\partial w}{\partial z}=0
$$

where $u, v$, and $w$ are the east, north, and upward velocity components in $x, y$, and $z$ directions, respectively. Equating the horizontal divergence with the vertical divergence we have

$$
\frac{\partial u}{\partial x}+\frac{\partial v}{\partial y}=-\frac{\partial w}{\partial z} \approx-\frac{w_{z=0}-w_{z=-30 \mathrm{~m}}}{30 \mathrm{~m}} .
$$

Using the magnitude of horizontal divergence in Fig. 1 averaged from $2^{\circ} \mathrm{S}$ to $2^{\circ} \mathrm{N}$ and from $25^{\circ} \mathrm{W}$ to $0^{\circ}(4.6 \times$ $10^{-7} \mathrm{~s}^{-1}$ ) and assuming no vertical velocity at the surface $\left(w_{z=0}=0\right)$ gives

$$
\begin{aligned}
w_{z=-30 \mathrm{~m}} & \approx 30 \mathrm{~m} \times 4.6 \times 10^{-7} \mathrm{~s}^{-1} \\
& \approx 1.4 \times 10^{-5} \mathrm{~m} \mathrm{~s}^{-1} \text { or } 1.2 \mathrm{~m} \mathrm{day}^{-1} .
\end{aligned}
$$

This shows that upwelling at $30 \mathrm{~m}$ on the order of meters per day can arise from surface divergence of the order $10^{-7} \mathrm{~s}^{-1}$. These magnitudes for divergence and 
upwelling are consistent with other single point estimates of equatorial upwelling for the equatorial Atlantic (Weingartner and Weisberg, 1991a) and for the Pacific (Weisberg and Qiao, 2000).

To estimate the magnitude of the equatorial upwelling volume transport, consider a zonal strip of the Atlantic Ocean within $2^{\circ}$ of the equator. Averaging our estimate of $w$ (at $30 \mathrm{~m}$ ) over this strip from 1993 to 2003 and multiplying it by the area gives $15( \pm 6) \mathrm{Sv}(\mathrm{Sv} \equiv$ $\left.10^{6} \mathrm{~m}^{3} \mathrm{~s}^{-1}\right)$. For comparison, Grodsky and Carton (2002) estimated vertical transport from $8^{\circ} \mathrm{S}$ to $8^{\circ} \mathrm{N}$ using drifter data to be $26( \pm 8) \mathrm{Sv}$. Since we observe more than one-half of this transport within $2^{\circ}$ of the equator, this suggests that the bulk of the transport is at the equator, consistent with the visco-inertial dynamics described earlier.

\section{a. Equatorial divergence}

Equatorial divergence estimates from OSCAR surface currents analyzed for each month along the equator are shown in Figs. 6 and 7. Adopting statistical methods used in atmospheric sciences (Wilks 1995), we have plotted the median values $\left(q_{0.5}\right)$ for the divergence annual cycle with the lower and upper quartiles $\left(q_{0.25}\right.$ and $\left.q_{0.75}\right)$ and the minimum and maximum year values. The space and time domain is from $2.5^{\circ} \mathrm{S}$ to $2.5^{\circ} \mathrm{N}$, $25^{\circ} \mathrm{W}$ to $0^{\circ}$ for the record length from 1993 through 2005. [These latitude limits were selected based on the EOF divergence patterns in Fig. 10, where it shows that a large part of the divergence variance is within $2.5^{\circ}$ of the equator. The longitude limits were selected where winds are easterly on average (east of $0^{\circ}$, see Fig. 12) but the western limit is within the range of influence of the equatorial cold tongue.]

To avoid the potential errors due to the near-equatorial functional fitting procedure, the equatorial divergence calculated in Figs. 6 and 7 (and also in Fig. 12) was performed using the midlatitude formulation (1) of the OSCAR current analysis. Since the equatorial approximation (2) is optimized only for the total surface current estimate, these methods are adopted when Ekman and geostrophic contributions are analyzed separately. To avoid the breakdown of the Ekman and geostrophic divergence near the equator only the solution at $2.5^{\circ}$ from the equator is used. To make the meridional divergence we take the difference between the $v$ velocity at $2.5^{\circ} \mathrm{N}$ and $2.5^{\circ} \mathrm{S}$. The zonal divergence is the average of two center differences at $2.5^{\circ} \mathrm{S}$ and $2.5^{\circ} \mathrm{N}$. In this way the divergence is calculated safely by avoiding the near-equator estimates. Further discussion of equatorial divergence calculated from (1) is provided in appendix $C$. The result is that we can calculate divergence
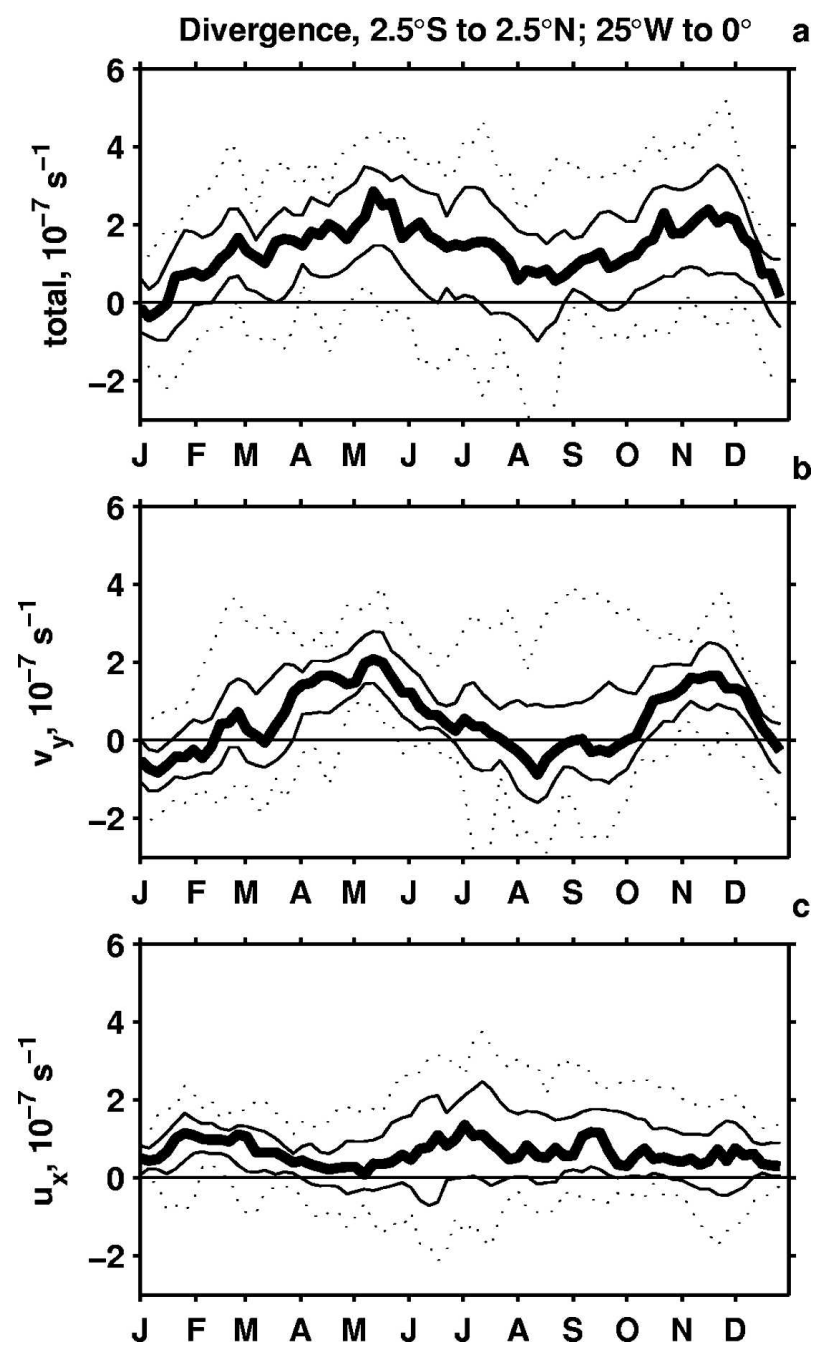

FIG. 6. Surface current equatorial (a) total divergence and (b) $v$ and (c) $u$ components from nonfitted OSCAR currents for a box bounded from $3^{\circ} \mathrm{S}$ to $3^{\circ} \mathrm{N}, 25^{\circ} \mathrm{W}$ to $0^{\circ}$ over the annual cycle for the years 1993-2005. The heavy solid line represents the median while the lighter solid lines represent the lower and upper quartiles. The dotted lines represent the minimum and maximum year values.

on the equator component by component for the Ekman and geostrophic constituents without potential error due to the equatorial fitting procedure.

The divergence magnitudes are similar to results from point measurements at moorings previously mentioned and also divergence magnitudes estimated from drifters near the equator in the Pacific Ocean (Hansen and Paul 1987). For the present analysis in the Atlantic Ocean, two seasons of strong divergence peak in May and November (Fig. 6a) and coincide with the same seasonality in the easterly winds resulting in Ekman divergence at the equator. Analysis of tropical Atlantic divergence from surface drifters exhibits a peak in May 

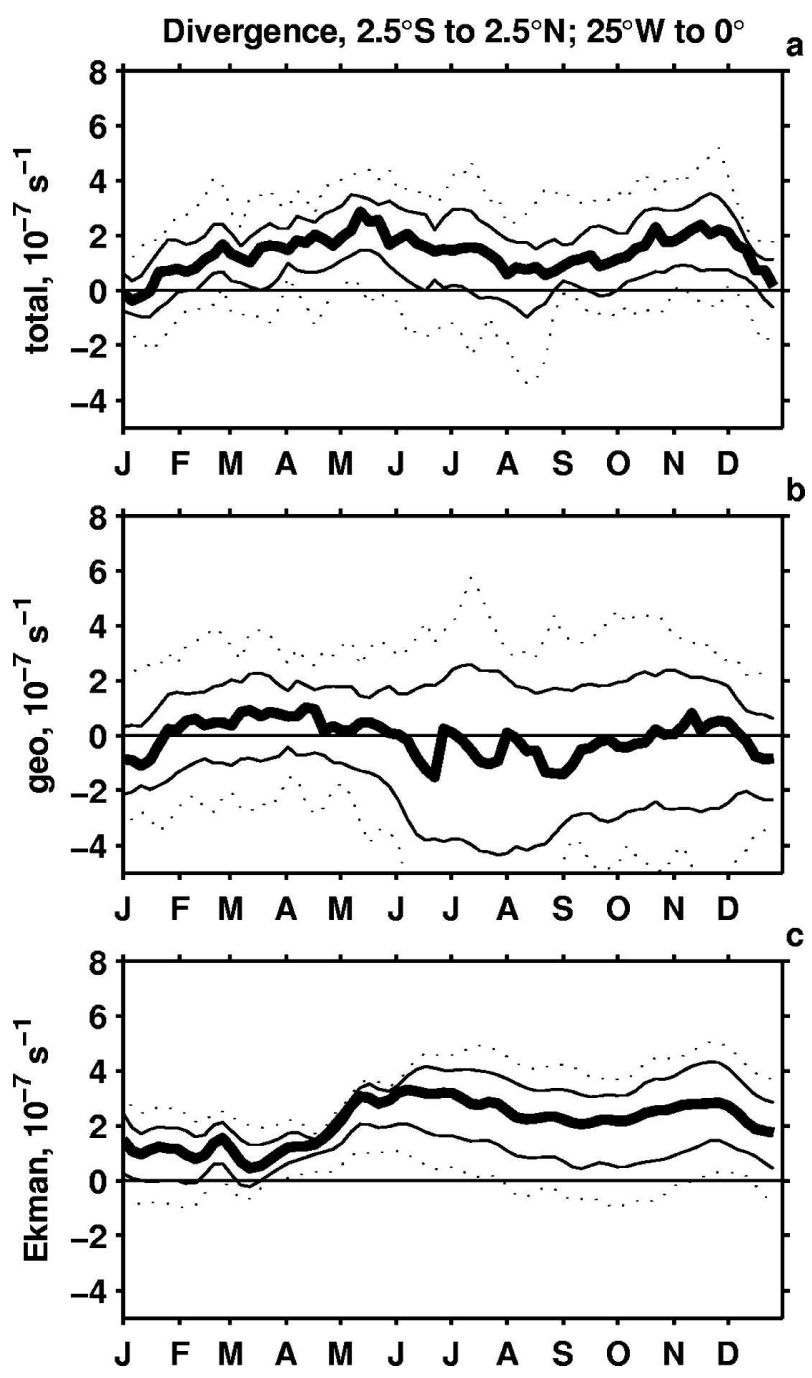

FIG. 7. Surface current equatorial (a) total, (b) geostrophic, and (c) Ekman divergence from nonfitted OSCAR currents for a box bounded by from $3^{\circ} \mathrm{S}$ to $3^{\circ} \mathrm{N}$ and from $25^{\circ} \mathrm{W}$ to $0^{\circ}$ over the annual cycle for the years 1993-2005. The heavy solid line represents the median while the lighter solid lines represent the lower and upper quartiles. The dotted lines represent the minimum and maximum year values.

but not in November (R. Lumpkin 2005, personal communication).

Meridional divergence has the largest contribution to the total divergence except in January/February and late summer/early autumn when zonal divergence is larger (Figs. 6b and 6c). While the zonal divergence is relatively small, it cannot be neglected, as demonstrated for the equatorial cold tongue regions of the Atlantic and Pacific by Weisberg and Weingartner (1988), Weingartner and Weisberg (1991a,b), and Weisberg and Qiao (2000). While parts of the two divergence components cancel (see appendix C), in situ observations of both provide a valuable diagnostic tool.
Separating the equatorial divergence, instead, into its dynaimical components we see that Ekman flow tends to diverge (Fig. 7). Geostrophic flow converges on average but exhibits seasons of divergence in boreal spring and November. The essential seasonality comes from the Ekman divergence due to easterly winds but is enhanced by the geostrophic divergence. Estimates of chlorophyll- $a$ and primary production show higher values that peak on the equator in August and December 2001 (Pérez et al. 2005) suggesting that production lags upwelling.

\section{b. Seasonal variability}

A lowest-order check of the surface current divergence is how well it agrees qualitatively with the major features of tropical Atlantic variability such as the annual movement of the ITCZ and the associated SST patterns. In particular, we expect to find cool (warm) SST associated with divergence (convergence). Where this association is not found is an indication of nonsteady dynamics or regions where ocean dynamics are relatively unimportant. During boreal spring the ITCZ is farthest south, SST is warmest near the equator, and the SEC is relatively strong. To illustrate this, climatologically averaged OSCAR divergence and AVHRR Pathfinder SST for the years of 1993 through 2003 are shown in Fig. 8. In March, the surface current convergence coincides with the warmest water in the east, off the African coast (Fig. 8a). Farther eastward SST is cooler on the equator where divergence occurs. During boreal autumn, while the ITCZ is farthest north, the Western Hemisphere warm pool (WHWP) is largest (Wang and Enfield 2003) and the NECC is strong (Fig. 8c). In November, the patterns of warmest (coolest) SST differ from the patterns of surface current convergence (divergence) (Fig. 8d), suggesting that many factors are influencing SST such as the thermocline adjustment and surface heat fluxes. During May a transition occurs when equatorial SST begins to decrease and the SEC magnitude on the equator increases (Figs. $8 \mathrm{~b}$ and 2), marking the annual response to wind forcing that can be largely accounted for by forced linear equatorial wave dynamics (Weisberg and Tang 1987, 1990). May is also a time when surface current divergence tends to be large (Fig. 6). Consistent with the divergence patterns, the equatorial cold tongue begins to appear first on the equator at midbasin, while the coldest SST appears farther toward the east shortly afterward (Fig. 12e) as the thermocline tilts up toward the east in adjustment to the increased wind. November also exhibits large equatorial divergence (Figs. 5 and 6) that may be explained by forced wave responses to zonal forcing plus subse- 

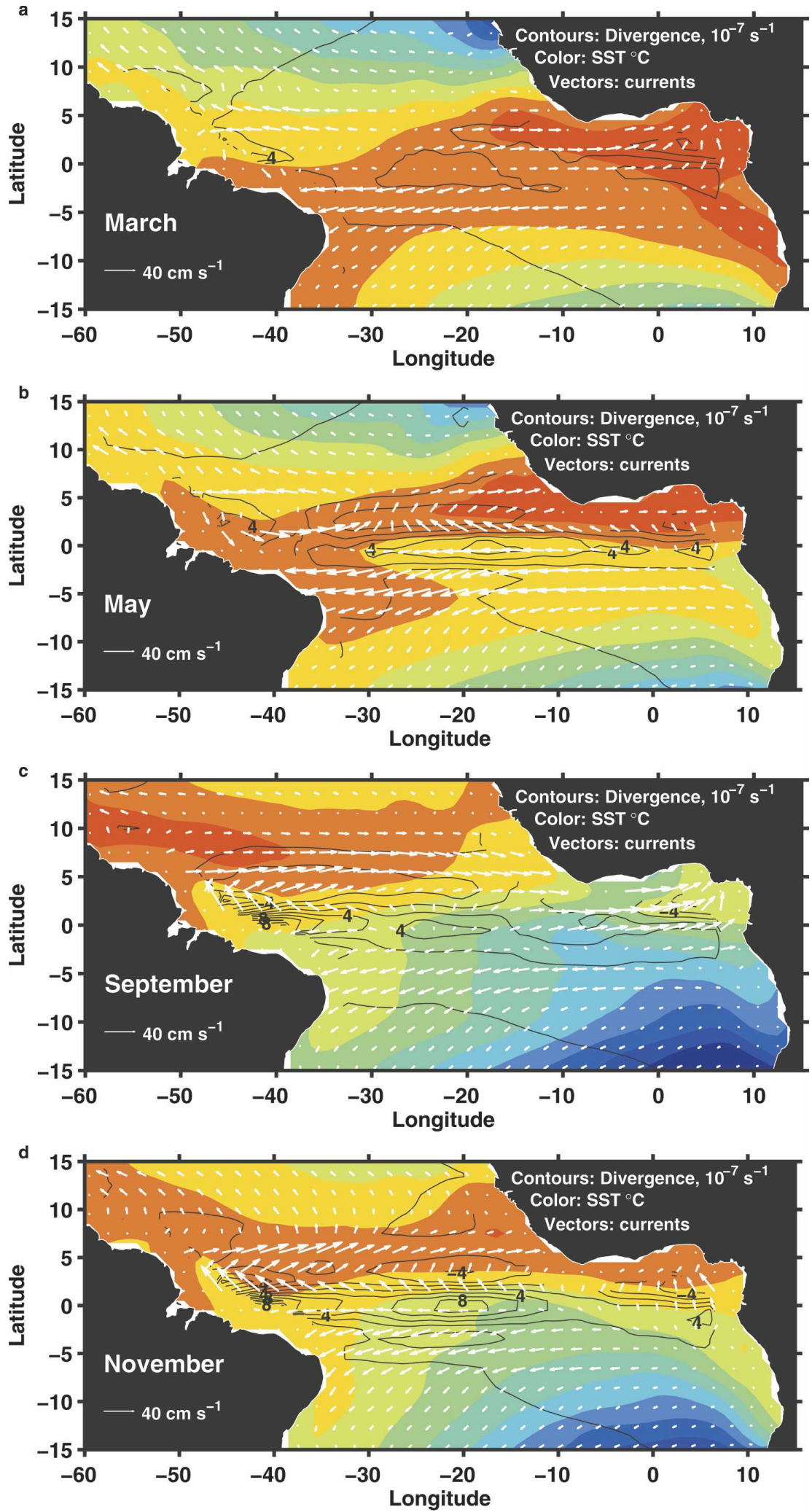

FIG. 8. Climatological averages from 1993 through 2002 for the months of (a) March, (b) May, (c) September, and (d) November of Pathfinder AVHRR SST and OSCAR surface current vectors and divergence. The black contour line interval is $2 \times 10^{-7} \mathrm{~s}^{-1}$. Negative divergence (convergence) has dash-dot contour lines. Arrows represent average surface current vectors. 

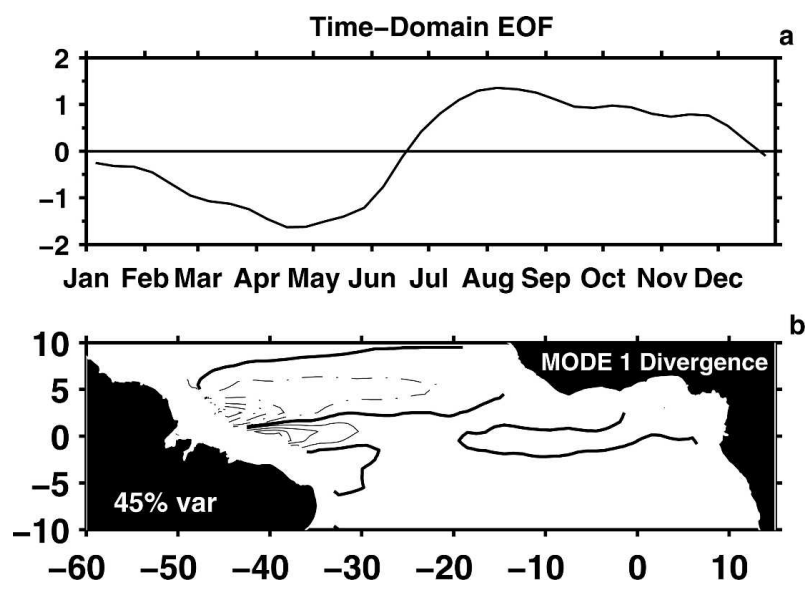

FIG. 9. The (a) time evolution functions and (b) spatial eigenfunctions for mode 1 from an EOF analysis performed on the climatologically averaged (1993-2003) surface currents divergence. The contour interval is $1 \times 10^{-7} \mathrm{~s}^{-1}$ with negative contours in dash-dot lines.

quent boundary reflections (Philander and Pacanowski 1986; Weisberg and Tang 1987, 1990).

\section{c. EOF modes}

Similarly to the velocity components, the seasonal variability of divergence is also investigated through EOF analysis. The first mode captures $45 \%$ of the total variance and represents the annual cycle of divergence (Fig. 9). In the spring/summer when the ITCZ is farthest south and the WHWP is small, relatively strong divergence (cooling/upwelling) occurs in the western portion of the Atlantic Ocean just north of a zero line that cuts across the basin from $\sim 1^{\circ} \mathrm{N}$ in the west to $\sim 5^{\circ} \mathrm{N}$ in the east. Along the equator in the west relatively strong convergence (warming/downwelling) occurs at this time. In the autumn/winter the opposite occurs. This divergence pattern cycle is consistent with the annual north/south migration of the ITCZ. The large variance in the western portion of the tropical Atlantic is also consistent with the large surface current variance due to the North Brazil Current that flows northward across the equator and then feeds the NECC in the spring.

The second EOF mode captures $23 \%$ of the total variance and represents the equatorial upwelling (divergence) that begins in late spring (Fig. 10). During this time of year SST decreases on the equator, as the ITCZ moves northward. In the autumn, after the ITCZ is at its northernmost position SST on the equator is increasing from its boreal spring/summer minimum since the thermocline is deeper and the surface heat fluxes provide a warming. During this part of the an-
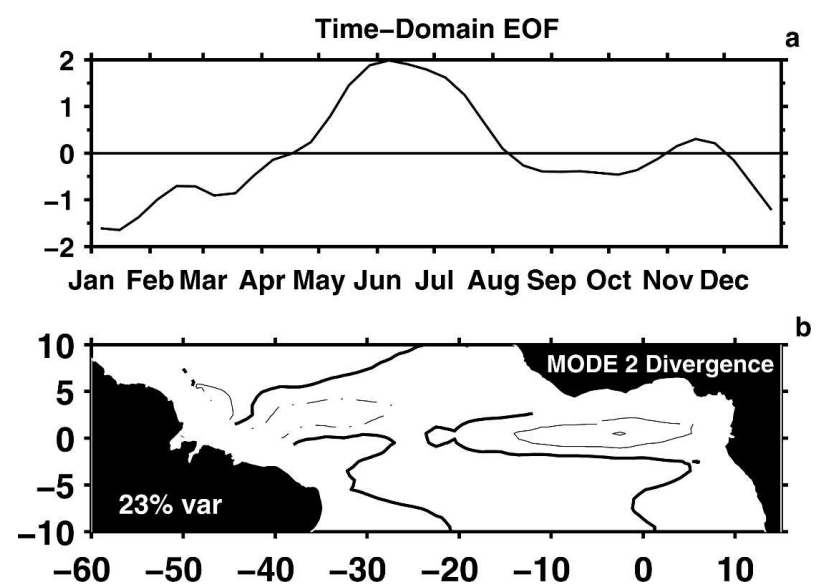

FIG. 10. As in Fig. 9 but for mode 2.

nual cycle strong divergence again occurs at the equator in November over the west/central portion of the basin as captured in the third mode ( $16 \%$ of the total variance, Fig. 11).

Three time-domain modes are required to capture the majority of the divergence variability for several reasons. Divergence estimates are inherently noisy at all time scales, as suggested by the large interquartile range in Figs. 6 and 7; there exists interannual variability in the tropical Atlantic Ocean (e.g., Jochum et al. 2004); and there exists phase gradients in space and time due to the thermocline evolution by forced equatorial wave propagation. Similar EOF calculations were performed on the full 11 years of data instead of the annual cycle, and only two modes were required to capture the same variability. The combination of the time evolution function and the spatial eigenvalues represented upwelling clearly in May and November for

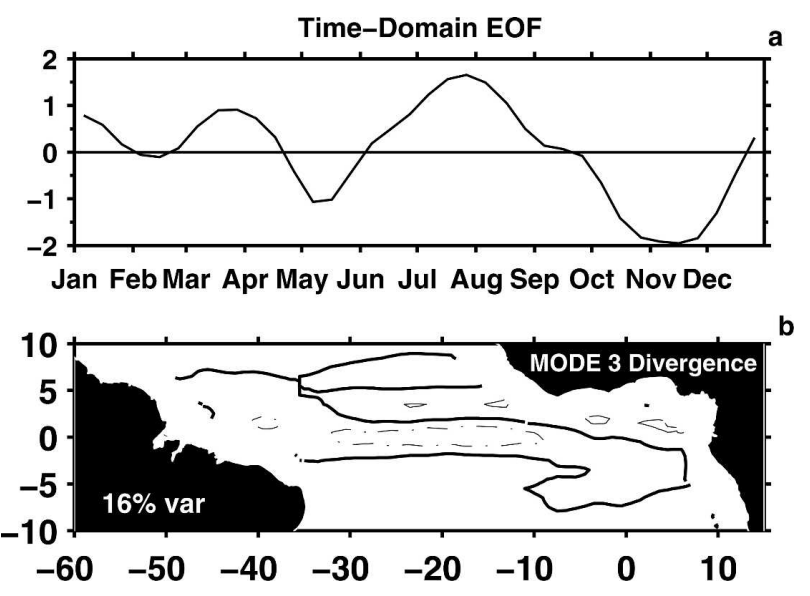

FIG. 11. As in Fig. 9 but for mode 3. 
most years, but in 1997, 1999, and 2000 the secondary divergence in November is absent. This suggests that in the annual cycle EOF analysis it is the interannual variability that increases the number of modes needed to describe the annual divergence cycle.

\section{d. Relation to SST and winds}

In this section, the relationship between the surface current divergence along the equator, tropical Atlantic SST, and zonal winds is evaluated. In addition to Ekman divergence and geostophic convergence, discussed in section 2, a linear balance of zonal pressure gradient and winds stress will occur at the equator and is given by (e.g., Philander and Pacanowski 1980)

$$
g \frac{\partial \zeta}{\partial x}=\frac{\tau^{x}}{h}
$$

where zonal wind stress, $\tau^{x}$, is taken to act like a body force over a given depth $h$. This balances in the steady state with zonal pressure gradient force, or equivalently the zonal sea surface slope $\partial \zeta / \partial x$, where $g$ is the acceleration of gravity. Where pressure is high, or the surface height is high, SST is warm. This balance, with the addition of a buoyancy term, is also a key consideration in the construction of the OSCAR model at the equator (BL02).

Since the time scales of interest in the present analysis are relatively long, the steady-state balance is the focus of the discussion but the adjustment of the thermocline associated with rapidly changing winds leads to the resulting balance. For example, linear equatorial wave dynamics suggests that the sudden onset of easterlies results in the generation of Kelvin and Rossby waves that initially cause the zonal pressure gradient to overshoot the steady-state conditions (as observed by Weisberg and Weingartner 1986) until the reflected Rossby waves return across the basin from the eastern boundary (Weisberg and Tang 1987). The point of the following analysis is that horizontal divergence associated with these adjustments and the eventual steadystate balance can be discerned from satellite-derived surface currents. While surface heat fluxes do have a role, their influence is diminished near the equator where ocean dynamics are important (Foltz et al. 2003; Yu et al. 2006).

In Fig. 12 the Ekman and geostrophic constituents of the OSCAR surface current divergence from $2.5^{\circ} \mathrm{S}$ to $2.5^{\circ} \mathrm{N}$ (calculated as described in section 5a and appendix C) in anomaly form (Figs. 12b and 12d) are displayed separately to show these constituent influences on the resultant divergence field (Fig. 12c) for the annual cycle. To place the divergence within the context of the equatorial Atlantic annual variability, zonal winds (as a proxy for wind stress) and SST are also displayed (Figs. 12a and 12e). The upper panels represent the record-length mean values for the corresponding anomaly data contoured directly below. The higher wavenumber variability seen in the geostrophic divergence is reflective of the variability scales in the SSH data, while the Ekman divergence reflects the variability scales found in the surface wind field. The total divergence contains a combination of these scales.

The underlying annual cycle of SST and zonal wind anomalies is characterized by a sudden onset of easterlies in May prior to the annual decrease of SST on the equator (Figs. 12a and 12e). What is suggested in Fig. 12 is that upper-ocean divergence provides a dynamical link between the observed variability of surface winds and SST. The zonal winds and Ekman divergence (Figs. $12 \mathrm{a}$ and $12 \mathrm{~b}$ ) have the same pattern with opposite sign because negative zonal winds represent easterlies that produce positive divergence (upwelling/cooling) at the equator. In late spring when the easterlies rapidly increase there is a clear connection between SST and divergence. During this time the strong easterlies drive strong Ekman divergence that cools the near surface temperature through upwelling.

Geostrophic divergence tends to be zero in both the mean and the anomaly (Fig. 12d) where SST has the maximum variance (near $10^{\circ} \mathrm{W}$ ). For example, in April when the SST anomaly is maximum at $10^{\circ} \mathrm{W}$ the geostrophic divergence anomaly is near zero. At this time, west of $10^{\circ} \mathrm{W}$ anomalous geostrophic divergence is positive and east of $10^{\circ} \mathrm{W}$ it is negative. This is consistent with the analysis of divergence from (1) as discussed in appendix C. West of $10^{\circ} \mathrm{W}$ SSH anomalously slopes up toward the east since SST is also anomalously warmer toward the east. From the geostrophic term in the divergence equation in (C6) in appendix $\mathrm{C}$, this produces divergence. East of $10^{\circ} \mathrm{W}$ the opposite occurs. Conversely, this observation suggests a similar pattern regarding thermocline depth where west of $10^{\circ} \mathrm{W}$ the thermocline anomalously slopes down toward the east and east of $10^{\circ} \mathrm{W}$ the opposite occurs. The situation is reversed in July and August when the SST is a minimum at $10^{\circ} \mathrm{W}$.

The average zonal wind (Fig. 12a, top panel) crosses zero near the prime meridian, which is just east of the maximum in SST cooling during boreal summer and early autumn. The steady-state momentum balance implies thermocline extrema where the winds stress is zero, and this argument was used by Weisberg and 

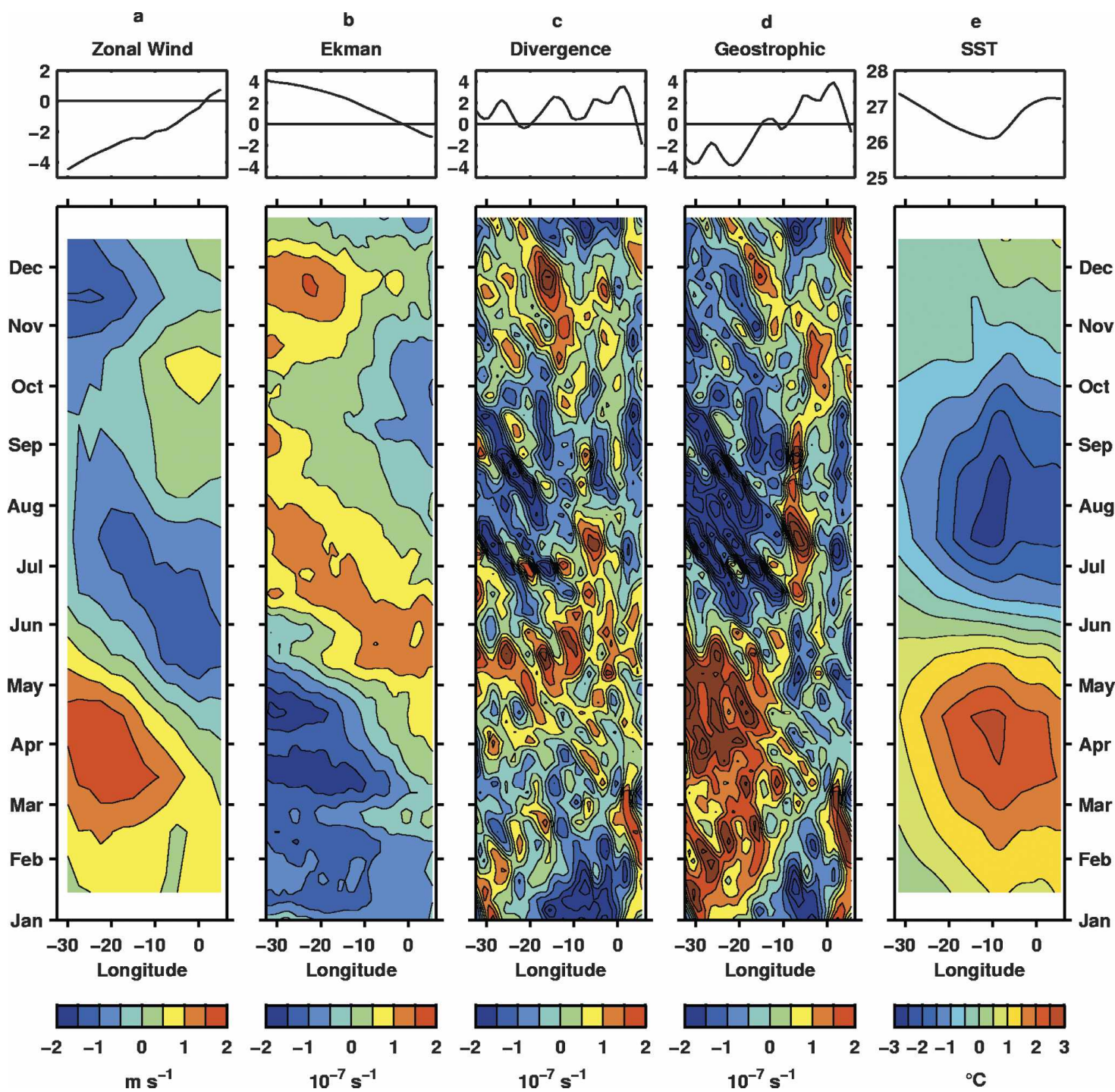

FIG. 12. Time vs longitude contours of (a) NCEP surface zonal winds, (b) Ekman, (c) total, and (d) geostrophic component surface current divergence, and (e) SST anomalies (total - mean) across the equatorial Atlantic Ocean. Winds and SST are averaged from $1.5^{\circ} \mathrm{S}$ to $1.5^{\circ} \mathrm{N}$, and divergence is computed from nonfitted OSCAR currents as described in section 5a. Plotted on the top of each contour are the corresponding record length mean values. Units for winds, divergence, and SST: $\mathrm{m} \mathrm{s}^{-1}, 10^{-7} \mathrm{~s}^{-1}$, and ${ }^{\circ} \mathrm{C}$.

Tang (1983) to account for the maximum in SST cooing observed there.

The total surface current divergence anomaly exhibits seasons of upwelling in the central/eastern equatorial Atlantic that peak in May and November within the equatorial cold tongue (Fig. 6). In May the increase of total divergence anomaly coincides with the most rapid SST cooling between $25^{\circ}$ and $5^{\circ} \mathrm{W}$ (Fig. 12e). In November the strongest divergence is farther toward the west and is coincident with a slight decrease in SST warming. On average, geostrophic flow converges while Ekman flow diverges about the equator west of $10^{\circ} \mathrm{W}$
(Figs. 12b and 12d, top panels) as a result of equatorial dynamics described in section 2. Strong Ekman divergence anomaly occurs in May/June/July and again in November in response to the easterly winds (Figs. 12a and 12b). The average Ekman divergence also crosses zero near $0^{\circ}$, consistent with the zero crossing of the zonal winds. In contrast, geostrophic convergence is due to the underlying thermocline structure that influences the surface height field. The geostrophic component exhibits strong convergence (divergence) anomaly in the western basin (from $35^{\circ}$ to $15^{\circ} \mathrm{W}$ ) during March, April, and May (July and August). 


\section{Conclusions}

The satellite-derived OSCAR surface current analyses are shown to be useful for diagnosing tropical ocean currents and horizontal current (mass) divergence in relation to Ekman and geostrophic dynamics. The zonal current space and time variability agrees well with the annual cycle of in situ ship-drift and drifter observations with regard to the NECC, the SEC, and equatorial divergence. The horizontal divergence variability agrees well with the seasonal evolution of the Atlantic subtropical gyre associated with the annual movement of the ITCZ, the equatorial gyre associated with the NECC/SEC complex, and the equatorial cold tongue. At certain times of the year the patterns of divergence differ from patterns of SST, suggesting that surface heat fluxes and mixing play a role in determining tropical Atlantic SST variability.

It is demonstrated that, while the meridional surface velocity component is weaker than the zonal component, meridional divergence provides the primary control on equatorial upwelling in the tropical Atlantic Ocean. For a box from $3^{\circ} \mathrm{S}$ to $3^{\circ} \mathrm{N}, 25^{\circ} \mathrm{W}$ to $0^{\circ}$ Ekman flow tends to diverge with seasonal peaks in May and November. Since the Ekman flow tends to be stronger than the geostrophic flow, there is a net surface divergence along the equator in the Atlantic Ocean. While Ekman divergence is a response to zonal wind stress, geostrophic divergence comes from the subsurface temperature structure and the resulting SSH gradient. The record length average of vertical transport at $30-\mathrm{m}$ depth, when averaged across the equatorial Atlantic Ocean between $2^{\circ} \mathrm{S}$ and $2^{\circ} \mathrm{N}$, is $15( \pm 6) \times 10^{6} \mathrm{~m}^{3} \mathrm{~s}^{-1}$. Although the zonal divergence tends to be weaker than meridional divergence, it is not negligible, and investigations of tropical ocean divergence need to consider both.

While this analysis lacks heat flux information and cannot make quantitative statements about heat transport, the annual cycle of surface current divergence is consistent with the seasonal north-south movement of the ITCZ and tropical SST. There are three main modes of variability in surface current divergence. The first represents the seasonal cycle in relation to the ITCZ and the off-equatorial currents. The second mode represents the equatorial upwelling peak in May, while the third mode captures the upwelling in November. This semiannual variability is also found in tropical SST and winds fields.

With the continued deployment of space-based observations, this approach establishes a new observational method for monitoring tropical currents through geostrophic and Ekman responses to external forcing.
While a full heat transport analysis is required to quantify the influence of divergence on the temperature balance of the tropical Atlantic, the dynamics evidence on the equator provided through the OSCAR analysis is sufficiently consistent with previous inferences from in situ (mooring) data (Weingartner and Weisberg 1991a,b) and thermocline evolution analyses by linear equatorial wave responses (Weisberg and Tang 1990) to suggest causality between equatorial SST and the underlying dynamics of upwelling, as ameliorated through surface fluxes and mixing. With these methods, in conjunction with other types of analyses, we may gain a better understanding of the tropical oceans in general. In addition, these observations may be useful in data assimilation systems or in the validation of numerical predictions.

Acknowledgments. Funding support by NOAA Office of Global Programs Grant NA16GP1571 is greatly appreciated. We thank our three anonymous reviewers for providing valuable suggestions that lead to substantial improvements to this manuscript; R. Lumkin at NOAA's Atlantic Oceanographic and Meteorological Laboratory provided helpful discussions and the climatological tropical Atlantic surface drifter data for which the authors are very grateful. We also thank J. Dastugue for help with graphics.

\section{APPENDIX A}

\section{Variance of the Ship-Drift Data}

To demonstrate the types of variance found in surface current climatologies, consider the ship-drift data used in Figs. 2 and 3. Most of the data are from the 1920s through the 1940s and occur primarily along shipping lanes. There are certain seasons where the data are sparse. In Fig. A1, ship-drift currents at $3^{\circ} \mathrm{N}$ for November are shown within the interquartile range and the minimum and maximum values for each longitude. The large variance is due in part to geophysical errors that arise from the natural variability of geophysical observations. Interannual variability is a likely source of this variance. The variance that cannot be accounted for by geophysical variability is due to measurement and representation errors. For example, the ship-drift values represent the average velocity between two way points that may about $100 \mathrm{~km}$ apart, while drifter arrays observations are on a much finer scale. As far as errors are concerned, wind drag on the ships is a primary source of error in the ship-drift dataset. This is the "leeway error" and is inherent in the ship-drift data (Richardson 1997). This is likely to reduce the accuracy and 

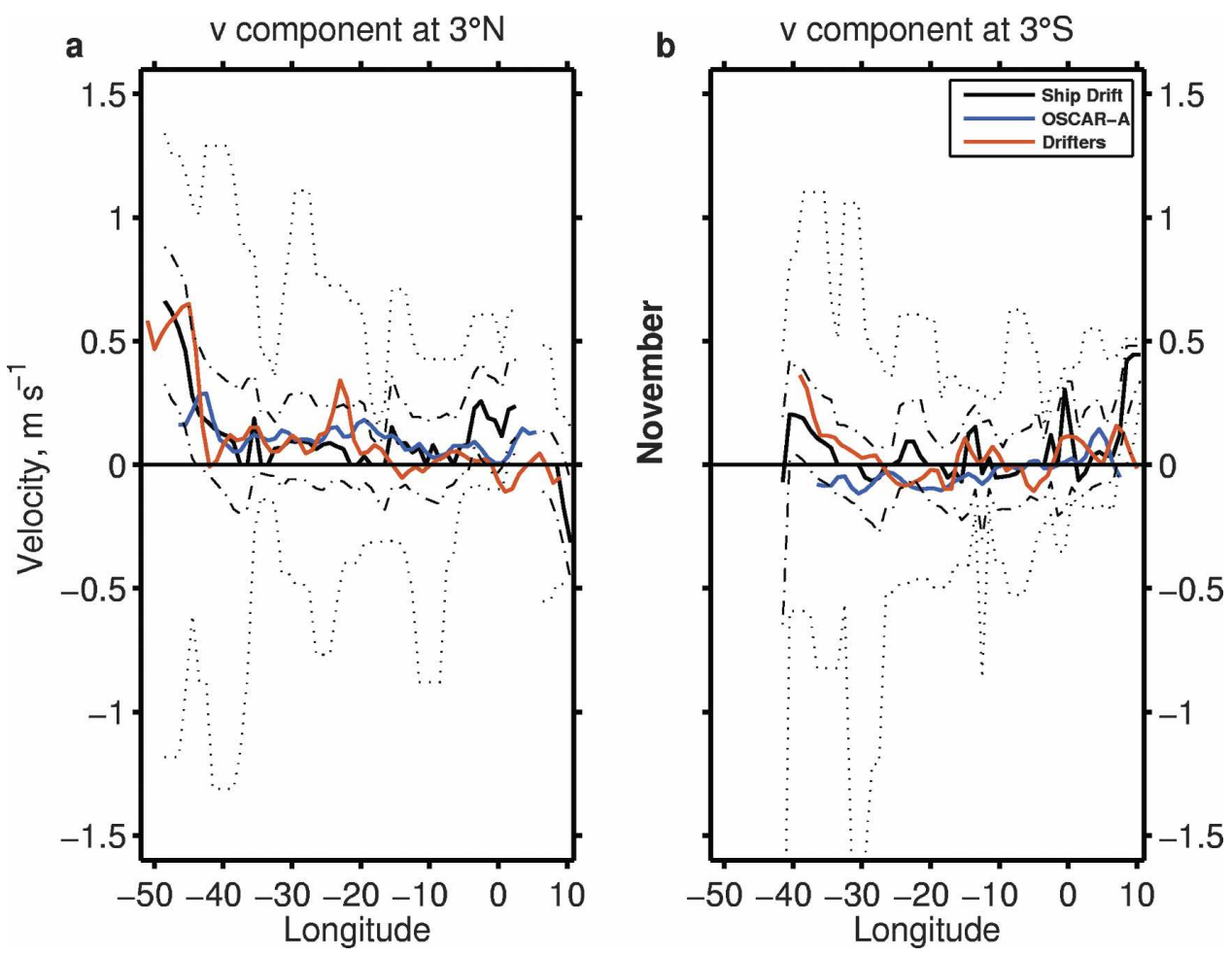

FIG. A1. A comparison of meridional velocity for November at (a) $3^{\circ} \mathrm{N}$ and (b) $3^{\circ} \mathrm{S}$ from ship-drift (black), OSCAR (blue), and surface drifter (red) observations. For the ship-drift observations the interquartile range is represented by the thin dash-dot lines, and the min and max values for each longitude are represented by the thin dotted lines.

precision of the observations. In addition, some regions and times are sparsely covered with data.

\section{APPENDIX B}

\section{Ancillary Evidence of OSCAR Divergence Validity}

To demonstrate that OSCAR currents provide physically consistent results near the equator, we compare divergence with the vertical motion of the thermocline as observed from the PIRATA array mooring located on the equator at $23^{\circ} \mathrm{W}$. Figure B1 shows the rms of isotherm vertical motion and OSCAR divergence, the sign-preserving square root of their covariance, and their correlation.

From the PIRATA observations the shallowest isotherm was chosen that is deeper than $30 \mathrm{~m}$ for the duration of the data (1993 through 2004 for this calculation). Isotherm choice had little influence on the resulting vertical displacements, implying that local divergence is dominated by currents shallower than about 30 $\mathrm{m}$. Therefore the isotherm vertical displacement was used as the vertical velocity at the bottom of the OSCAR layer $(30 \mathrm{~m})$. From the continuity equation we have for a finite difference over the 30-m surface layer

$$
\frac{w_{z=0}-w_{z=30}}{-30}+\frac{\partial u}{\partial x}+\frac{\partial v}{\partial y}=0,
$$

or where $w_{z=0}=0$ we have

$$
\frac{\partial u}{\partial x}+\frac{\partial v}{\partial y}=-\frac{w_{z=30}}{30}
$$

Where mixing and horizontal advection can be neglected we can estimate vertical velocity from the vertical movement of the isotherm:

$$
w_{z=30} \approx \frac{\partial h_{i s o}}{\partial t} .
$$

This relationship will not hold over all scales but provides a qualitative reference for comparison with the OSCAR derived divergence.

The OSCAR divergence was spatially filtered such that the half-amplitude response is at the zonal/meridional wavelength denoted in Fig. B1. The result preserves two degrees of freedom per half-amplitude wavelength. Temporal bands were created by using 
$23^{\circ}$ Isotherm/OSCAR Divergence Statistics, c00n023w
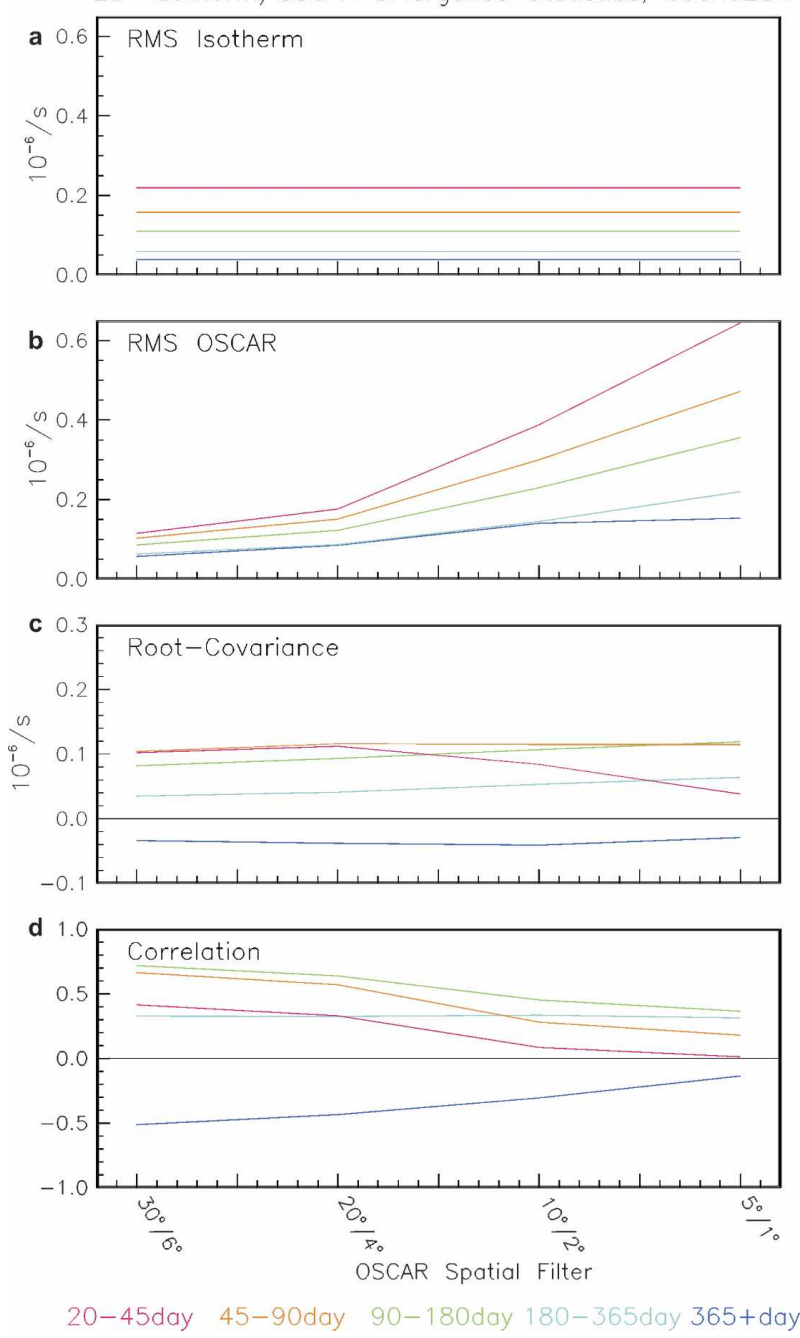

FIG. B1. Rms of (a) isotherm divergence, (b) OSCAR divergence, and the (c) root covariance, and (d) correlation between the isotherm and OSCAR divergence. The horizontal axis represents the scale over which the OSCAR divergence has been filtered in zonal/meridional degrees and the line colors are for the period bands listed at the bottom.

various low-pass filters identified by their half-amplitude response, calculating statistics for each low-passed time series and then differencing the results (e.g., Johnson et al. 2007). This approach allows gappy data to be used (in the case of the PIRATA data) and also ensures that variance is preserved in the total.

The correlation between OSCAR- and isothermderived divergence is largest for the intermediate period bands (Fig. B1d). At longer periods, entrainment (mixing) potentially becomes important and the correlation goes down. The mooring at $0^{\circ}, 23^{\circ} \mathrm{W}$ was chosen because it is the most centralized location away from the complicating influence of the ocean boundaries.
This comparison is done on the equator because that is where divergence (upwelling) is largest.

\section{APPENDIX C}

\section{Equatorial Divergence from the Midlatitude Formulation}

Equation (1) in section 3 is formulated for use at midlatitudes and is only valid approximately $2.5^{\circ}$ from the equator. Equation (2) is an equatorial approximation, but the method for fitting the equatorial solution with the midlatitude solution is optimized with Ekman, geostrophic, and buoyancy components summed together. Therefore, to evaluate divergence about the equator with geostrophic and Ekman dynamics separated, consider (1) in expanded complex notation:

$$
u_{0}+i v_{0}=\frac{g}{f}\left(i \frac{\partial \zeta}{\partial x}-\frac{\partial \zeta}{\partial y}\right)-\frac{1}{f H} \mathbf{q}\left(\frac{H}{\hbar_{e}}\right)\left(i \tau^{x}-\tau^{y}\right)
$$

For this treatment buoyancy forcing has been ignored since it provides only a minor correction relative to geostrophic and Ekman flows. Before going further we must consider the function

$$
\mathbf{q}\left(\frac{H}{\hbar_{e}}\right)=\frac{H / \hbar_{e}}{\tanh \left(H / \hbar_{e}\right)},
$$

where $\hbar_{e}=\sqrt{A / i f}$. This is a complex number and therefore $\mathbf{q}$ has zonal and meridional components. To simplify (C1) we use $\mathbf{q}$ in the form

$$
\frac{\mathbf{q}\left(H / \hbar_{e}\right)}{f H}=E^{\operatorname{Re}}(f)+i E^{\operatorname{Im}}(f),
$$

where

$$
E^{\mathrm{Re}}=\frac{1}{f H} \frac{z(\cosh 2 z+\cos 2 z)}{(\sinh 2 z)^{2}+(\sin 2 z)^{2}}(\sinh 2 z+\sin 2 z)
$$

and

$$
E^{\mathrm{Im}}=\frac{1}{f H} \frac{z(\cosh 2 z+\cos 2 z)}{(\sinh 2 z)^{2}+(\sin 2 z)^{2}}(\sinh 2 z-\sin 2 z),
$$

and where $z=H[f /(2 A)]^{1 / 2}$. Then $(\mathrm{C} 1)$ becomes

$$
u_{0}+i v_{0}=\frac{g}{f}\left(i \frac{\partial \zeta}{\partial x}-\frac{\partial \zeta}{\partial y}\right)-\left(E^{\operatorname{Re}}+i E^{\operatorname{Im}}\right)\left(i \tau^{x}-\tau^{y}\right)
$$

The two horizontal velocity components separately are

$$
u_{0}=-\frac{g}{f} \frac{\partial \zeta}{\partial y}+E^{\mathrm{Re}} \tau^{y}+E^{\operatorname{Im}} \tau^{x}
$$




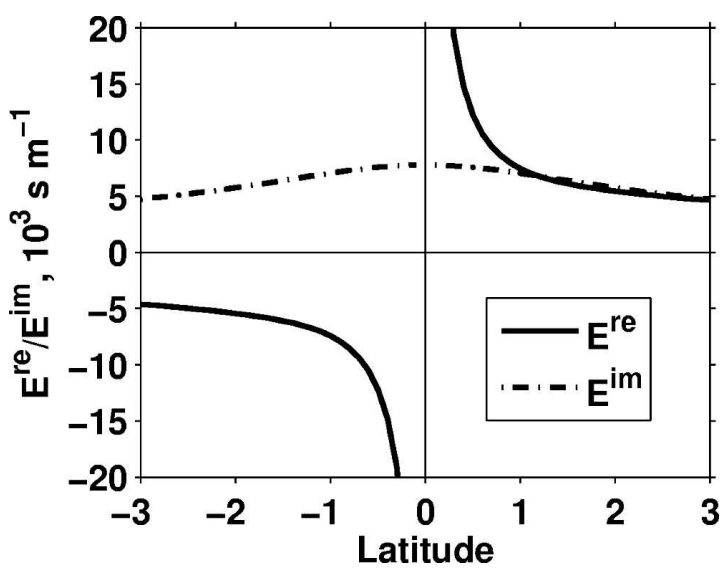

FIG. C1. The values of the real $E^{\mathrm{Re}}$ and imaginary $\left(E^{\mathrm{Im}}\right)$ parts of $\mathbf{q}\left(H / \hbar_{e}\right) / f H$ vs latitude.

and

$$
v_{0}=\frac{g}{f} \frac{\partial \zeta}{\partial x}-E^{\mathrm{Re}} \tau^{x}+E^{\operatorname{Im}} \tau^{y} .
$$

Using (C2) and (C3), the zonal and meridional components of divergence become

$$
\frac{\partial u_{0}}{\partial x}=-\frac{g}{f} \frac{\partial^{2} \zeta}{\partial x \partial y}+E^{\operatorname{Re}} \frac{\partial \tau^{y}}{\partial x}+E^{\operatorname{Im}} \frac{\partial \tau^{x}}{\partial x}
$$

and

$$
\begin{aligned}
\frac{\partial v_{0}}{\partial y}= & -\frac{g \beta}{f^{2}} \frac{\partial \zeta}{\partial x}+\frac{g}{f} \frac{\partial^{2} \zeta}{\partial y \partial x}-\frac{\partial E^{\operatorname{Re}}}{\partial y} \tau^{x}-E^{\operatorname{Re}} \frac{\partial \tau^{x}}{\partial y} \\
& +\frac{\partial E^{\operatorname{Im}}}{\partial y} \tau^{y}+E^{\operatorname{Im}} \frac{\partial \tau^{y}}{\partial y},
\end{aligned}
$$

where $\beta=\partial f / \partial y$. To avoid the equatorial singularity, zonal divergence in sections 5a and 5d (Figs. 6, 7, and 12) is calculated by averaging the zonal divergence given by (C4) at $2.5^{\circ} \mathrm{N}$ and $2.5^{\circ} \mathrm{S}$. While the zonal currents can differ from $2.5^{\circ} \mathrm{N} / \mathrm{S}$ to the equator, making the equator divergence using the equatorial estimate (2) did not change the results qualitatively. This may be because the first term on the right-hand side of (C4) cancels with the same term of opposite sign in (C5). This is a result of geostrophic nondivergence in the absence of $\beta$. For the calculation of the divergence components separately (Fig. 6c), the first term may dominate. This is because in the second term $E^{\mathrm{Re}}$ is antisymmetric (Fig. C1), making the $2.5^{\circ} \mathrm{N} / \mathrm{S}$ values tend to cancel. The third term is small since the zonal length scale of the zonal wind stress is large.

Because $f=0$ at the equator, meridional divergence (C5) becomes singular. To avoid this, meridional divergence at the equator is calculated by taking the differ- ence in $v_{0}$ at $2.5^{\circ} \mathrm{N} / \mathrm{S}$ divided by the separation in meters. Written explicitly in terms of (C3), we have

$$
\begin{aligned}
\frac{\partial v_{0}}{\partial y} \approx & \frac{\left.v_{0}\right|_{y=2.5}-\left.v_{0}\right|_{y=-2.5}}{\Delta y} \\
= & \frac{1}{\Delta y}\left(\frac{g}{f} \frac{\partial \zeta}{\partial x}-E^{\operatorname{Re}} \tau^{x}+E^{\operatorname{Im}} \tau^{y}\right)_{y=2.5} \\
& -\frac{1}{\Delta y}\left(\frac{g}{f} \frac{\partial \zeta}{\partial x}-E^{\operatorname{Re}} \tau^{x}+E^{\operatorname{Im}} \tau^{y}\right)_{y=-2.5} .
\end{aligned}
$$

Since at $2.5^{\circ} \mathrm{N} / \mathrm{S} E^{\mathrm{Re}}$ and $E^{\mathrm{Im}}$ are nearly the same magnitude and $\tau^{x} \gg \tau^{y}$ at the equator, we neglect $\tau^{y}$. Then considering the asymmetry of $f$ and $E^{\mathrm{Re}}$ we have

$$
\frac{\partial v_{0}}{\partial y} \approx \frac{2 g}{|f| \Delta y} \frac{\partial \zeta}{\partial x}-2\left|E^{\mathrm{Re}}\right| \tau^{x} .
$$

It is also assumed that $\tau^{x}$ and $\partial \zeta / \partial x$ do not vary within $2.5^{\circ}$ of the equator. While this is not entirely true, the remaining terms on the right-hand side of (C6) are the dominant contributions to divergence at the equator. The first term represents the geostrophic contribution and is related to the zonal slope of the sea surface such that it is positive (negative) representing divergence (convergence) when the SSH slopes up toward the east (west). This can be seen in Fig. 12 and is discussed in section $5 \mathrm{~d}$. The primary term in equatorial divergence is the second term on the right-hand side of (C6) that represents Ekman divergence, which is strong due to the easterly trade winds $\left(\tau^{x}<0\right)$ that prevail over the tropical ocean. Meridional winds are relatively weak in the equatorial ocean and have been neglected in this simplified treatment.

\section{REFERENCES}

Atlas, R., R. Hoffman, S. Bloom, J. Jusem, and J. Ardizzone, 1996: A multiyear global surface wind velocity dataset using SSM/I wind observations. Bull. Amer. Meteor. Soc., 77, 869882.

Bonjean, F., and G. S. E. Lagerloef, 2002: Diagnostic model and analysis of the surface currents in the tropical Pacific Ocean. J. Phys. Oceanogr., 32, 2938-2954.

Bryden, H. L., and E. C. Brady, 1985: Diagnostic model of the three-dimensional circulation in the upper equatorial Pacific Ocean. J. Phys. Oceanogr., 15, 1255-1273.

Cane, M. E., 1980: On the dynamics of equatorial currents, with application to the Indian Ocean. Deep-Sea Res., 27A, 525544.

Carton, J. A., and Z. Zhou, 1997: Annual cycle of sea surface temperature in the tropical Atlantic Ocean. J. Geophys. Res., 102, $27813-27824$.

— X. Cao, B. S. Giese, and A. M. da Silva, 1996: Decadal and interannual SST variability in the tropical Atlantic Ocean. $J$. Phys. Oceanogr., 26, 1165-1175.

Chang, P., L. Ji, and H. Li, 1997: A decadal climate variation in the tropical Atlantic Ocean from thermodynamic air-sea interactions. Nature, $\mathbf{3 8 5}, 516-518$. 
Charney, J. G., 1960: Non-linear theory of a wind-driven homogeneous layer near the equator. Deep-Sea Res., 6, 303-310.

—_, and S. Spiegel, 1971: Structure of wind-driven equatorial currents in homogeneous oceans. J. Phys. Oceanogr., 1, 149160.

Fofonoff, N. P., and R. B. Montgomery, 1955: The Equatorial Undercurrent in the light of the vorticity equation. Tellus, 7, 518-521.

Foltz, G. R., S. A. Grodsky, and J. A. Carton, 2003: Seasonal mixed layer heat budget for the tropical Atlantic Ocean. $J$. Geophys. Res., 108, 3146, doi:10.1029/202JC001584.

Fonseca, C. A., G. J. Goni, W. E. Johns, and E. J. D. Campos, 2004: Investigation of the North Brazil Current retroflection and North Equatorial Countercurrent variability. Geophys. Res. Lett., 31, L21304, doi:10.1029/2004GL020054.

Grodsky, S. A., and J. A. Carton, 2002: Surface drifter pathways originating in the equatorial Atlantic cold tongue. Geophys. Res. Lett., 29, 2147, doi:10.1029/2002GL015788.

Hansen, D. V., and C. A. Paul, 1987: Vertical motion in the eastern equatorial Pacific inferred from drifting buoys. Oceanol. Acta, 6, 27-32.

Helber, R. W., and R. H. Weisberg, 2001: Equatorial upwelling in the western Pacific warm pool. J. Geophys. Res., 106, 89899003.

Jochum, M., R. Murtugudde, P. Malanotte-Rizzoli, and A. J. Busalacchi, 2004: Internal variabilitiy of the tropical Atlantic Ocean. Earth's Climate: The Ocean-Atmosphere Interaction, Geophys. Monogr., Vol. 147, Amer. Geophys. Union, 181188.

Johnson, E. S., F. Bonjean, G. S. E. Lagerloef, J. T. Gunn, and G. T. Mitchum, 2007: Validation and error analysis of OSCAR sea surface currents. J. Atmos. Oceanic Technol., 24, 688-701.

Lagerloef, G. S. E., G. T. Mitchum, R. B. Lukas, and P. P. Niiler, 1999: Tropical Pacific near-surface currents estimated from altimeter, wind, and drifter data. J. Geophys. Res., 104, $23313-23326$.

Lumpkin, R., and Z. Garraffo, 2005: Evaluating the decomposition of tropical Atlantic drifter observations J. Atmos. Oceanic Technol., 22, 1403-1415.

— cal Atlantic Ocean. Deep-Sea Res. I, 52, 495-518.

Mayer, D. A., and R. H. Weisberg, 1993: A description of COADS surface meteorological fields and the implied Sverdrup transports for the Atlantic Ocean from $30^{\circ} \mathrm{S}$ to $60^{\circ} \mathrm{N}$. $J$. Phys. Oceanogr., 23, 2201-2221.

Meinen, C. S., M. J. McPhaden, and G. C. Johnson, 2001: Vertical velocities and transports in the equatorial Pacific during 1993-99. J. Phys. Oceanogr., 31, 3230-3248.

Molinari, R., S. Bauer, D. Snowden, G. Johnson, B. Bourles, and Y. Gouriou, 2003: A comparison of kinematic evidence for tropical cells in the Atlantic and Pacific Oceans. Interhemispheric Water Exchange in the Atlantic Ocean, G. J. Goni and P. Malanotte-Rizzoli, Eds., Elsevier Oceanography Series, Vol. 68, Elsevier, 269-286.

Okumura, Y., and S.-P. Xie, 2006: Some overlooked features of tropical Atlantic climate leading to a new Niño-like phenomenon. J. Climate, 19, 5859-5874.

Pazan, S. E., and P. P. Niiler, 2001: Recovery of near-surface velocity from undrogued drifters. J. Atmos. Oceanic Technol., 18, 476-489.

Pérez, V., E. Fernandez, E. Maranon, P. Serret, and C. GarciaSoto, 2005: Seasonal and interannual variability of chloro- phyll a and primary production in the equatorial Atlantic: In situ and remote sensing observations. J. Plankton Res., 27, 189-197.

Philander, S. G. H., and R. C. Pacanowski, 1980: The generation of equatorial currents. J. Geophys. Res., 85, 1123-1136.

_, and - 1986: A model of the seasonal cycle in the tropical Atlantic Ocean. J. Geophys. Res., 91, 14 192-14 206.

Qiao, L., and R. H. Weisberg, 1997: The zonal momentum balance of the Equatorial Undercurrent in the central Pacific. $J$. Phys. Oceanogr., 27, 1094-1119.

Richardson, P. L., 1997: Drifting in the wind: Leeway error in shipdrift data. Deep-Sea Res., 44, 1877-1903.

_ and T. K. McKee, 1984: Average seasonal variation of the Atlantic equatorial currents from historical ship drifts. $J$. Phys. Oceanogr., 14, 1226-1238.

Santiago-Mandujano, F., and E. Firing, 1990: Mixed-layer shear generated by wind stress in the central equatorial Pacific. $J$. Phys. Oceanogr., 20, 1576-1582.

Saravanan, R., and P. Chang, 2004: Thermodynamic coupling and predictability of tropical sea surface temperature. Earth's Climate: The Ocean-Atmosphere Interaction, Geophys. Monogr., Vol. 147, Amer. Geophys. Union, 171-180.

Stommel, H., 1960: Wind-drift near the equator. Deep-Sea Res., 6, 298-302.

Wang, C., 2005: Subthermocline tropical cells and equatorial subsurface countercurrents. Deep-Sea Res. I, 52, 123-135.

- and D. Enfield, 2003: A further study of the tropical Western Hemisphere warm pool. J. Climate, 16, 1476-1493.

-, S.-P. Xie, and J. A. Carton, 2004: A global survey of oceanatmosphere interaction and climate variability. Earth's Climate: The Ocean-Atmosphere Interaction, Geophys. Monogr. Vol. 147, Amer. Geophys. Union, 1-19.

Weingartner, T. J., and R. H. Weisberg, 1991a: On the annual cycle of equatorial upwelling in the central Atlantic Ocean. $J$. Phys. Oceanogr., 21, 68-82.

— and - 1991b: A description of the annual cycle in sea surface temperature and upper ocean heat in the equatorial Atlantic. J. Phys. Oceanogr., 21, 83-96.

Weisberg, R. H., and T. Y. Tang, 1983: Equatorial ocean response to growing and moving wind systems with application to the Atlantic. J. Mar. Res., 41, 461-486.

, and T. J. Weingartner, 1986: On the baroclinic response of the zonal pressure-gradient in the equatorial Atlantic-Ocean. J. Geophys. Res., 91, 1717-1725.

_ and T. Y. Tang, 1987: Further studies on the response of the equatorial thermocline in the Atlantic Ocean to the seasonaly varying trade winds. J. Geophys. Res., 92, 3709-3727.

_ , and T. J. Weingartner, 1988: Instability waves in the equatorial Atlantic Ocean. J. Phys. Oceanogr., 18, 1641-1657. , and T. Y. Tang, 1990: A linear analysis of equatorial Atlantic Ocean thermocline variability. J. Phys. Oceanogr., 20, $1813-1825$.

- , and L. Qiao, 2000: Equatorial upwelling in the central Pacific estimated from moored velocity profiles. J. Phys. Oceanogr., 30, 105-124.

Wilks, D. S., 1995: Statistical Methods in the Atmospheric Sciences: An Introduction. Academic Press, 467 pp.

Xie, S.-P., 1999: A dynamic ocean-atmosphere model of the tropical Atlantic decadal variability. J. Climate, 12, 64-70.

Yu, L., X. Jin, and R. A. Weller, 2006: Role of net surface heat flux in seasonal variations of sea surface temperature in the tropical Atlantic Ocean. J. Climate, 19, 6153-6169. 